\title{
IMPROVED CONFINEMENT IN TEXTOR
}

\author{
J. ONGENA ${ }^{1 *}$, H. CONRADS ${ }^{2}$, M. GAIGNEAUX ${ }^{1 \dagger}$, A.M. MESSIAEN ${ }^{1 *}$, \\ R.R. WEYNANTS ${ }^{1}$, E. BARBIAN ${ }^{2}$, G. BERTSCHINGER ${ }^{2}$, P. BORGERMANS ${ }^{1}$, \\ R.V. BUDNY ${ }^{4}$, T. DELVIGNE ${ }^{1}$, P. DUMORTIER ${ }^{1}$, F. DURODIE ${ }^{1}$, H.G. ESSER ${ }^{2}$, \\ H. EURINGER ${ }^{2}$, G. FUCHS ${ }^{2}$, B. GIESEN ${ }^{2}$, E. GRAFFMANN ${ }^{2}$, D.L. HILLIS ${ }^{3}$, \\ F. HOENEN ${ }^{2}$, P. HÜTTEMANN ${ }^{2}$, M. JADOUL ${ }^{1}$, H. KEVER ${ }^{2}$, R. KOCH ${ }^{1}$, \\ W. KOHLHAAS ${ }^{2}$, L. KÖNEN ${ }^{2}$, M. KORTEN ${ }^{2}$, H.R. KOSLOWSKI ${ }^{2}$, \\ A. KRÄMER-FLECKEN ${ }^{2}$, M. LOCHTER ${ }^{2}$, G. MANK ${ }^{2}$, A. POSPIESZCZYK ${ }^{2}$, \\ U. SAMM ${ }^{2}$, B. SCHWEER ${ }^{2}$, H. SOLTWISCH ${ }^{2}$, G. TELESCA ${ }^{2}$, R. UHLEMANN ${ }^{2}$, \\ P.E. VANDENPLAS ${ }^{1}$, R. VAN NIEUWENHOVE ${ }^{1 *}$, G. VAN OOST ${ }^{1}$, M. VERVIER ${ }^{1}$, \\ G. VAN WASSENHOVE ${ }^{1}$, G. WAIDMANN ${ }^{2}$, J. WINTER ${ }^{2}$, G.H. WOLF ${ }^{2}$ \\ 1 Laboratoire de physique des plasmas - Laboratorium voor Plasmafysica, \\ Association Euratom-Etat Belge - Associatie Euratom-Belgische Staat, \\ Ecole royale militaire - Koninklijke Militaire School, \\ Brussels, Belgium \\ 2 Institut für Plasmaphysik, \\ Forschungszentrum Jülich, GmbH, \\ Association Euratom-KFA, \\ Jülich, Germany \\ 3 Oak Ridge National Laboratory, \\ Oak Ridge, Tennessee, \\ United States of America \\ 4 Princeton Plasma Physics Laboratory, \\ Princeton, New Jersey, \\ United States of America
}

\begin{abstract}
A new regime of enhanced confinement (I-mode) is found in plasmas with circular cross-section in the pump limiter tokamak TEXTOR with boronized walls. This regime is obtained with three types of auxiliary heating, namely NBI co-injection, NBI counter-injection + ICRH and NBI co-injection + NBI counter-injection, and has many similarities with the $\mathrm{H}$-mode regime obtained in divertor tokamaks. The energy confinement times obtained in these discharges scale as favourably as those in stationary $\mathrm{H}$-mode discharges with edge localized modes. A detailed analysis of the scaling of the confinement time with plasma current, heating power and plasma density is presented. Characteristic electron density and temperature profiles are observed, with large central values and well developed edge pedestals. They are compared with those found in H-mode discharges and supershots. A poloidal beta limit of 1.6 is found in the I-mode discharges of TEXTOR. The maximum toroidal beta values obtained reach nearly $1 \%$, i.e. 0.7 times the Troyon limit in TEXTOR. I-mode confinement is always linked with low recycling and absence of MHD activity. If these conditions are not met, L-mode scaling is retrieved. MHD activity, which is more likely to occur at low plasma densities and currents, can cause a sudden drop to L-mode scaling. So far, no transition from the L-mode scaling to the I-mode scaling has been observed.
\end{abstract}

\section{INTRODUCTION}

Enhanced energy confinement has been observed in the limiter tokamak TEXTOR. This new improved confinement regime (I-mode) can be attained with NBI coinjection (NBI-co), NBI co-injection plus NBI counterinjection (NBI-co + NBI-counter) and a combination of NBI co-injection and ion cyclotron resonance heating
(NBI-co + ICRH). The behaviour of the discharge exhibits many similarities with the $\mathrm{H}$-mode obtained on other tokamaks. It is the purpose of the present paper to describe the plasma behaviour under these enhanced confinement conditions.

In Refs [1] and [2] we reported that confinement results clearly in excess of the L-mode scaling were achieved in TEXTOR. In these studies, this regime

\footnotetext{
$\dagger$ Deceased.

* Researcher at National Fund for Scientific Research, Brussels, Belgium.
} 


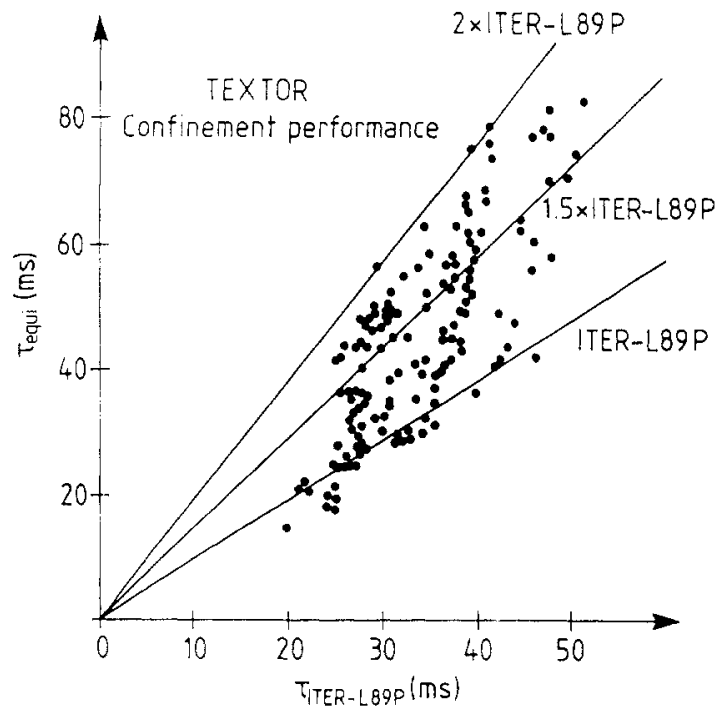

FIG. 1. Comparison of the confinement performance of TEXTOR with the predictions of the ITER L89-P scaling. The data points shown are obtained with many different heating scenarii, for $200<I_{p}<500 \mathrm{kA}, 1.8<\bar{n}_{e 0}<5.1 \times 10^{13} \mathrm{~cm}^{-3}$ and $1.5<P_{\text {tor }}<5.2 \mathrm{MW}$. The lines indicate the predictions of $1,1.5$ and 2 times ITER L89-P.

was qualified as 'improved' and termed the I-mode. Improved confinement can be achieved in stationary discharges over a wide range of plasma currents. The usual signature of the $\mathrm{H}$-mode, i.e. the $\mathrm{L}-\mathrm{H}$ transition, is not seen; no sudden changes of $\mathrm{D}_{\alpha}$, radiated power and edge density or temperature are observed. However, the improved confinement is almost as good as that of the so-called stationary ELMy H-mode of divertor tokamaks. The average stationary improvement in confinement time with respect to the L-mode is about a factor of 1.68 , and transiently the improvement can be much higher. The I-mode discharges are characterized by strong profile peaking; the edge density and temperature profiles near the limiter can be as steep as those in divertor ELMy $\mathrm{H}$-mode discharges obtained in machines of a similar size, density and plasma current.

To obtain the confinement results described in this paper, the tokamak TEXTOR has been operated with the following characteristics: large radius $R=1.75 \mathrm{~m}$, small radius $\mathrm{a}=0.46 \mathrm{~m}$, plasma current $\mathrm{I}_{\mathrm{p}}=200-500 \mathrm{kA}$ and toroidal field $\mathrm{B}_{\mathrm{t}}=2.2-2.4 \mathrm{~T}$. The plasma is circular in shape and is limited by the toroidal belt limiter ALT-II; the walls are boronized. The additional heating capability reaches a total of more than $7 \mathrm{MW}$, i.e. 1.7 MW of co-injection $\mathrm{D}^{0} \rightarrow \mathrm{D}^{+}$(NBI-co), $1.7 \mathrm{MW}$ of counter-injection $\mathrm{D}^{0} \rightarrow \mathrm{D}^{+}$(NBI-counter), with a maximum injection energy of $55 \mathrm{kV}$, and $4 \mathrm{MW}$ of ICRH ( $\mathrm{H}$ minority heating in $\mathrm{D}$ plasma).

The paper is organized as follows. The characteristics of the I-mode discharges are described in Section 2. Global confinement is discussed in Section 3. The detailed parameter dependence is presented in Section 4. The characteristics of the I-mode are compared with those of the H-mode and supershots in Section 5. The conditions for the I-mode are discussed in Section 6 and the conclusions are presented in Section 7.

\section{CHARACTERIZATION OF I-MODE DISCHARGES}

In analyses of the confinement performances of TEXTOR for the different heating methods and their combinations or for different machine conditions, a large scatter in the data is observed. An example is shown in Fig. 1, where the confinement times derived from the equilibrium (or MHD) energy for a large number of discharges are compared with the predictions from a standard scaling expression. For the latter, the ITER L89-P scaling law for standard L-mode confinement has been used. It can be seen that the confinement results are distributed between 0.7 and 2 times the ITER L89-P scaling. The points pertain to all heating scenarii, i.e. NBI-co, NBI-counter and ICRH or combinations. Upon closer analysis, it is found that the upper points belong to the heating scenarii NBI-co, NBI-co + NBI-counter and NBI-co + ICRH. The scatter within each of these heating modes is smaller than $25 \%$ (unless severe MHD activity sets in, see Section 6) and is partly due to the fact that individual points correspond to different plasma densities (see Section 4). The confinement improvement with respect to the L-mode discharge is substantial, hence the use of the qualifier 'improved' for this confinement regime. It is therefore called the I-mode and defined as the confinement regime obtained in NBI-co, NBI-co + NBI-counter or $\mathrm{NBI}-\mathrm{co}+\mathrm{ICRH}$ discharges with low MHD activity and low recycling.

A typical I-mode TEXTOR discharge, heated in a stepwise way, with both $1.8 \mathrm{MW}$ NBI-co-injection and 1.6 MW NBI-counter-injection, is illustrated in Fig. 2. Shown are the time evolution of the line averaged central density $\overline{\mathrm{n}}_{\mathrm{e} 0}$ (from the HCN interferometer), the measured central electron temperature $T_{e}(0)$ (measured by the ECE diagnostic), the central ion temperature (calculated by TRANSP [3] as explained below and checked by CXRS measurements), the equilibrium (or MHD) energy $E_{\text {equi }}$, the diamagnetic energy $E_{\text {dia }}$, the 


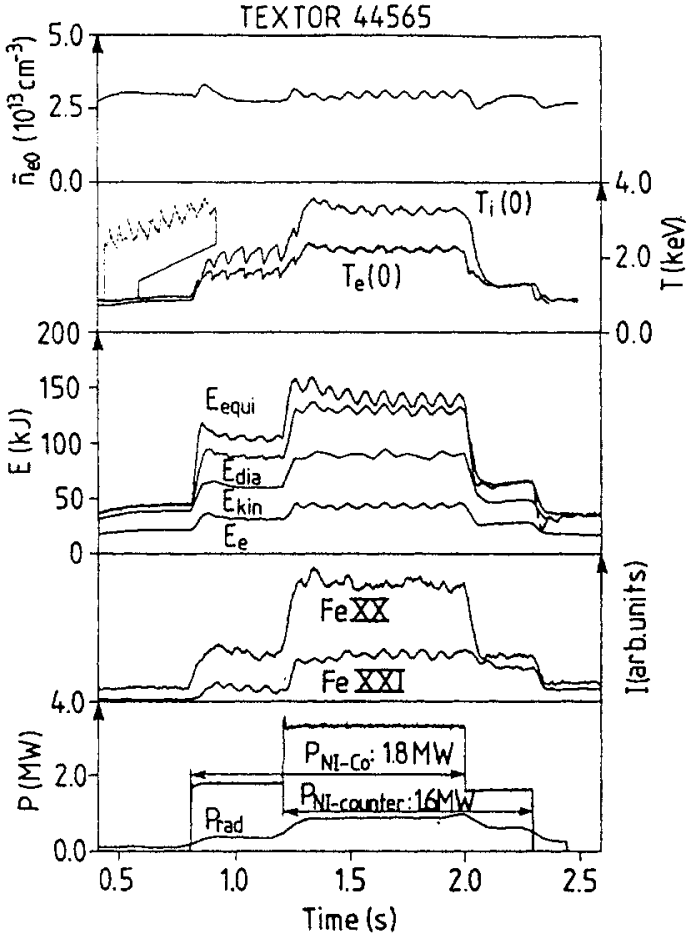

FIG. 2. Plasma parameters as a function of time for a TEXTOR $I$-mode discharge (\#44565, $I_{p}=400 \mathrm{kA}, B_{t}=2.25 \mathrm{~T}$ ) obtained with NBI-co-injection and nearly balanced NBI-co $+N B I$-counterinjection. Plotted is the time variation of the central line averaged electron density, the central ion and electron temperatures, different plasma energies, the $F e X X$ and $F e X X I$ brilliances, the total radiated power and the engineering values of the injected NBI-co and NBIcounter power. The inset shows the presence of sawteeth during the onmically heated phase of the discharge.

thermal energy content in the electrons, $E_{e}$ (from the integration of the product of $n_{e}(r)$ and $T_{e}(r)$ over the small tokamak radius), and the energy content in the electrons and ions of the plasma, $E_{k i n}$ or $E_{\text {th }}$ (using the temperature and density profiles of ions and electrons), the behaviour of the impurity lines Fe XX and Fe XXI, the engineering value of the power injected into the machine with co- and counter-injection, $\mathrm{P}_{\mathrm{NI}-\mathrm{co}}$ and $\mathrm{P}_{\text {NI.counter }}$ (not corrected for losses due to charge exchange and shinethrough), and the radiated power $P_{r a d}$ (from bolometry). Note that $E_{\text {equi }}$ is determined assuming that during the additional heating phase the value of the internal inductance $\ell_{i}$ does not change. With the help of TRANSP, we found, however, that the value of $\ell_{\mathrm{i}}$ generally decreases slightly (typical values are given in Table II). The value of $E_{\text {equi }}$ predicted by TRANSP from the computation of $E_{\mathrm{kin}}$ and the energy stored in the fast particles is generally higher than the experimental one. Thus, the experimental value of $E_{\text {equi }}$ used in this paper corresponds to a rather conservative estimation of the equilibrium energy.

Except for the small oscillation, which is seen on some of the signals and which is due to an oscillation of the feedback system for the density control, an overshoot is visible in the temperature and energy signals of this discharge at the beginning of the phases heated by NBI-co alone and with a combination of NBI-co and NBI-counter. This phenomenon is often seen during I-mode discharges and is most prominent in the equilibrium energy. In the following, we will therefore make a distinction between the data obtained under transient conditions, i.e. at the beginning of a heating phase, and stationary conditions, where the energies remain stationary for at least 20 times the energy confinement time. Note the difference between $E_{\text {equi }}$ or $E_{\text {dia }}$ and the thermal energy $E_{k i n}$; this difference is due to the presence of non-negligible suprathermal components in the plasma particle population.

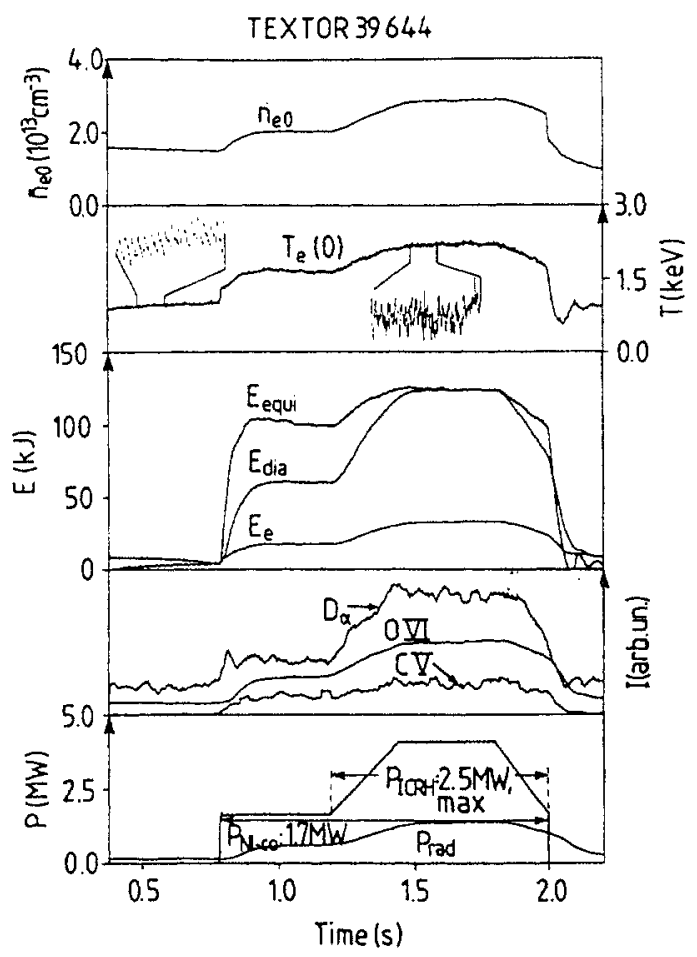

FIG. 3. Plasma parameters as a function of time for a TEXTOR $I$-mode discharge ( $\# 39644, I_{p}=340 \mathrm{kA}, B_{t}=2.25 \mathrm{~T}$ ) obtained with a combination of NBI-CO and ICRH. Shown are the same signals as in Fig. 2, except for the third box, where $E_{\text {kin }}$ has been omitted, and the fourth box, which shows the time evolution of the intensities of the $D_{\alpha}$ line and of the light impurity lines $O V I$ and $C V$. The insets show the presence of sawtooth activity during the ohmically heated phase and its absence during the combined NBI-co + ICRH phase. 


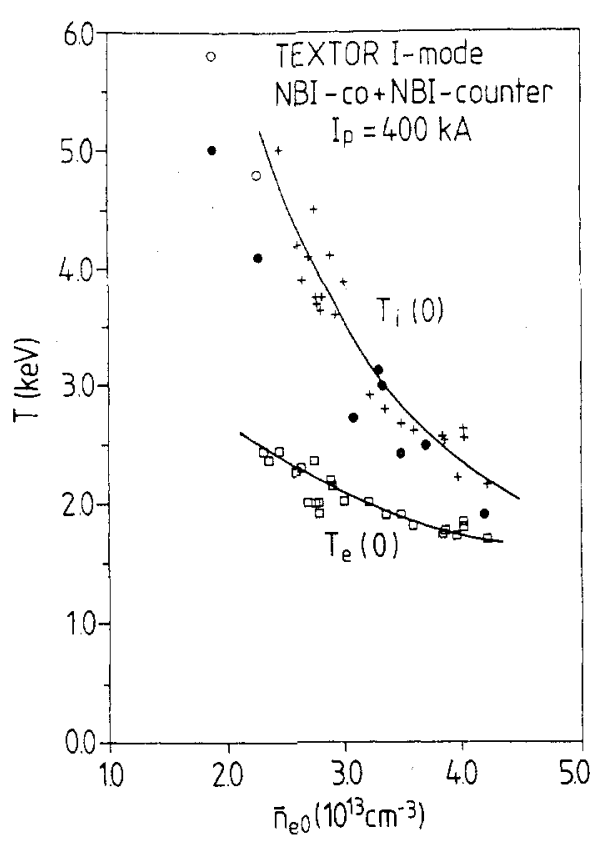

FIG. 4. Dependence of the central electron temperature (open squares, measured by the ECE diagnostic) and the central ion temperature (crosses, measured with the CXRS diagnostic) on the plasma density. Also shown are results of TRANSP simulations for $T_{i}(0)$, assuming $\chi_{i}=\chi_{e}$ (indicated by the closed dots) or $\chi_{i}=\frac{2}{3} \chi_{e}$ (indicated by the open dots). The data are taken from discharges with $I_{p}=400 \mathrm{kA}$ and $3.45<P_{\text {tot }}<3.75 \mathrm{MW}$.

In this discharge, the feedback density control is able to keep the value of the density constant, owing to a sufficiently small gas release of the wall during additional heating. This depends on the time history and the conditioning of the machine, which determine the degree of the deuterium release from the walls.

Essentially the same phenomenology is observed for I-mode discharges obtained with a combination of NBI-co and ICRH, an example of which is shown in Fig. 3. The plasma parameters shown are the same as those for the previous discharge, except for the central ion temperature and the thermal energy $E_{\mathrm{kin}}$, which were not available for this discharge, the impurity lines, which are now the light impurity lines $\mathrm{C} \mathrm{V}$ and $\mathrm{O}$ VI, and the $\mathrm{D}_{\alpha}$ signal at the limiter. Note that the latter trace does not show any sign of a transition that could reveal $\mathrm{H}$-mode behaviour. All observations are similar to those for the previous discharge, except that ICRH leads to a larger increase in the perpendicular energy compared to the parallel energy.

In contrast to the discharge in Fig. 2, the density rises during the additional heating phase owing to gas release from the wall.
The evolution of the central ion temperature (measured with CXRS) and the central electron temperature (from the ECE diagnostic) as a function of the line averaged central density is shown in Fig. 4 for TEXTOR I-mode discharges heated with a combination of NBI-co + NBI-counter at a plasma current of $400 \mathrm{kA}$. The central ion temperature for this type of discharges is always higher than the central electron temperature, thus exhibiting hot ion mode behaviour. Both temperatures are strongly dependent on the plasma density; the difference between $T_{e}(0)$ and $T_{i}(0)$ is maximum at low density $\left(\bar{n}_{\mathrm{e} 0}=2 \times 10^{13} \mathrm{~cm}^{-3}\right)$, where $T_{i}(0)$ is as high as $5 \mathrm{keV}$ and $\mathrm{T}_{\mathrm{e}}(0)$ is approximately $2.5 \mathrm{keV}$.

A low ratio of $P_{\text {rad }}$ to the total heating power is a characteristic feature for an I-mode discharge with boronized walls. The low stationary level of the radiated power indicates a low and stationary level of impurities in the discharge, as confirmed by measurements of the impurity lines Fe XX and Fe XXI in Fig. 2 and $\mathrm{CV}$ and $\mathrm{O}$ VI in Fig. 3. The profile of the radiated power pertaining to the discharge of Fig. 2 is given in Fig. 5. It is hollow in the centre, and retains this form for the whole duration of the I-mode discharge, confirming that there is no impurity accumulation in the core of the plasma during the I-mode.

The profiles of the electron density and temperature can be rather peaked and show steep gradients and pedestals near the edge of the plasma (see Section 5). A typical example of the evolution of the electron density and temperature profiles as a function of $\bar{n}_{e 0}$ is given in Fig. 6. Further details about the profiles in

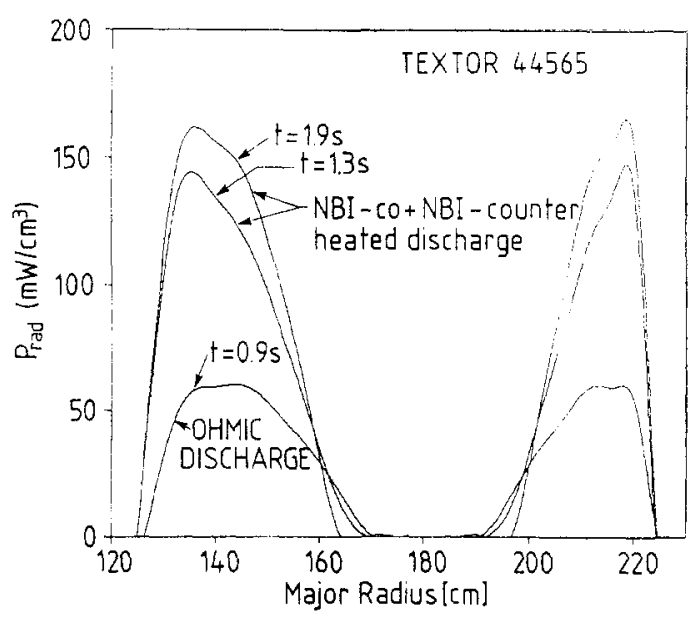

FIG. 5. Profile of the radiated power during the Ohmic and the NBI-co + NBI-counter I-mode phases of TEXTOR discharge \#44565. The plasma parameters for this discharge are the same as for the discharge shown in Fig. 2. 


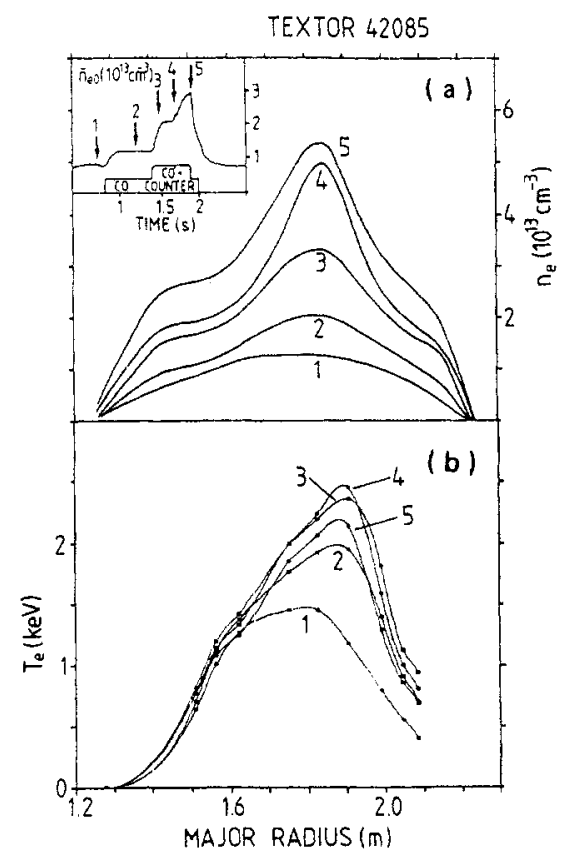

FIG. 6. Evolution of the profiles of (a) the electron density and (b) the electron temperature during a TEXTOR I-mode discharge (\#42085), for different values of the central line averaged electron density. The abrupt change in the density rise at time 4 is linked with an electrical breakdown in the plasma box of one of the neutral injectors.

the centre and at the edge are given in Section 5. As in the case of the discharge shown in Fig. 3, the density rise in this case is also due to gas release from the wall when additional heating is applied.

Sawteeth are often stabilized in I-mode discharges, as can be seen in Fig. 2. (The oscillations in Fig. 2 are due not to sawtooth activity but to an instability in the feedback system for plasma density control.) For the discharge in Fig. 3, the same phenomenon is observed: small sawteeth during the Ohmic phase of the discharge and absence of sawteeth during additional heating. In Refs [1] and [4], it was shown that NBI-co-injection alone was able to considerably stretch the sawteeth in TEXTOR, up to complete stabilization at sufficiently low plasma densities. The range of densities for which stabilization was obtained was larger at lower plasma currents. It was shown that the sawtooth-free phase is characterized by $\mathrm{q}_{0}<1$ and that the creation of a trapped hot ion population inside the $\mathrm{q}=1$ surface is essential for stabilization. The addition of ICRH to NBI-co-injection permits an extension of the domain in which stretching or even full stabilization of sawteeth occurs. This can be tentatively interpreted by the large increase, due to ICRH, in the perpendicular energy of the injected fast particles, which leads to an enhanced trapped hot ion population inside the $\mathrm{q}=1$ surface.

For the case of NBI-co + NBI-counter-injection, complete sawtooth stabilization is also observed. Although its occurrence is more erratic than for pure NBI-co and NBI-co + ICRH, complete stabilization is also more easily obtained in this case at low plasma densities and currents. Sawtoothing and sawtooth-free parts can be observed in the same discharge, and from TRANSP simulations we found that both phases are characterized by approximately the same $q$-profile with $\mathrm{q}_{0}<1$.

The neutron production during NBI-co-injection is mostly due to beam-target reactions. The fraction of neutrons produced by beam-beam reactions is roughly one order of magnitude less, as found by TRANSP simulations. The reactivity of the plasma is further enhanced during heating with NBI-co + ICRH. This is due to (i) an increase in the electron temperature, leading to enhancement of the slowing down time of the fast ions, and (ii) a decrease of the plasma bulk rotation observed during heating with NBI-co + ICRH [5], resulting in an increase in the beam-target reactions. Neutron production is maximum during balanced $\mathrm{NBI}$-co + NBI-counter-injection when the measured bulk plasma rotation is nearly zero. TRANSP simulations allow roughly $60 \%$ of the emitted neutrons to be attributed to beam-target reactions and the remainder almost exclusively to beam-beam reactions. Thermal fusion reactions contribute only a few per cent to the observed neutron yield. Maximum neutron source rates of $2 \times 10^{14} \mathrm{~s}^{-1}$ have been observed in such discharges, leading to a $Q_{D D}$ value of $7.3 \times 10^{-5}$ or an equivalent $Q_{D T}$ value of $1.7 \times 10^{-2}$ if the plasma and beam parameters of these deuterium plasmas are maintained in a 50/50 D-T plasma.

I-mode discharges heated with NBI-co + NBI-counter and NBI-co + ICRH can suddenly transit to a lower confinement regime. The frequency of the occurrence of these transitions increases with decreasing plasma current and density, and is linked with the occurrence of MHD activity, as seen on the electron temperature, electron density and Mirnov signals (see Section 6).

\section{GLOBAL CONFINEMENT SCALING OF THE TEXTOR I-MODE}

The ITER L89-P scaling law is used to compare the confinement quality of the TEXTOR I-mode with that of other machines. This scaling law is given by the expression (see Ref. [6]) 
ONGENA et al.

$\tau=0.038 \mathrm{~B}_{\mathrm{t}}^{0.2} \overline{\mathrm{n}}_{\mathrm{e} 0}^{0.1} \mathrm{I}_{\mathrm{p}}^{0.85} \mathrm{P}_{\mathrm{tot}}^{-0.5} \mathrm{R}^{1.2} \mathrm{a}^{0.3} \kappa^{0.5} \mathrm{~A}_{\mathrm{i}}^{0.5}$

with the units $\mathrm{s}(\tau), \mathrm{T}\left(\mathrm{B}_{\mathrm{t}}\right) 10^{13} \mathrm{~cm}^{-3}\left(\overline{\mathrm{n}}_{\mathrm{e} 0}\right)$, MA $\left(\mathrm{I}_{\mathrm{p}}\right)$, MW ( $\left(\mathrm{P}_{\text {tot }}\right), \mathrm{m}(\mathrm{R}, \mathrm{a}) ; \kappa$ is the elongation and $\mathrm{A}_{\mathrm{i}}$ is the ion mass.

The TEXTOR I-mode database is subject to the following criteria: The energy is the equilibrium (or MHD) energy $\mathrm{E}_{\text {equi }}$, and all discharges satisfy

$\frac{P_{\text {rad }}}{P_{\text {tot }}}<0.60$

$\frac{1}{P_{\text {tot }}} \frac{\mathrm{dE}_{\text {equi }}}{\mathrm{dt}}<0.10$

$\frac{E_{\text {fast }}}{E_{\text {equi }}}<0.40$

$E_{\text {fast }}$ is the energy stored in the fast particle population and is given by $\mathrm{E}_{\text {fast }}=\mathrm{E}_{\mathrm{tot}}-\mathrm{E}_{\mathrm{kin}}$, with $\mathrm{E}_{\mathrm{tot}}=\left(2 \mathrm{E}_{\text {equi }}\right.$ $\left.+E_{\text {dia }}\right) / 3 . P_{\text {tot }}$ is the total net heating power, which we set equal to the sum of the Ohmic power, the engineering value of the ICRH power launched into the machine, and the total injected beam power corrected for shinethrough and charge exchange losses. Note that the above criteria are more strict for the selection of $\mathrm{dE}_{\text {equi }} / \mathrm{dt}$ than those underlying the ITER H-mode database $[7,8]$.

A large number of TRANSP simulations resulted in the following formula for the conversion of the engineering value of the injected beam power $\mathrm{P}_{\mathrm{NI}}$ to the corrected net NBI heating power:

$\mathrm{P}_{\mathrm{NI}, \text { corr }}=\mathrm{P}_{\mathrm{NI}}\left(0.543+0.263 \times \ln \left(\overline{\mathrm{n}}_{\mathrm{e} 0}\right)\right)$

where $\overline{\mathrm{n}}_{\mathrm{e} 0}$ is expressed in $10^{13} \mathrm{~cm}^{-3}$ and with $1 \times 10^{13} \mathrm{~cm}^{-3}<\overline{\mathrm{n}}_{\mathrm{e} 0}<5 \times 10^{13} \mathrm{~cm}^{-3}$. No attempt was made to correct the ICRH or the NBI power values for non-optimal energy deposition $[9,10]$. In addition, no correction was applied to the ICRH power for boundary layer losses [11]. In this respect, it is important to note that the values of the NBI and the ICRH power are therefore not on the same footing [12].

The experimental values of the equilibrium confinement time $\tau_{\text {equi }}=\mathrm{E}_{\text {equi }} / \mathrm{P}_{\text {tot }}$ obtained in I-mode discharges are compared with the predictions of ITER L89-P in Figs $7 \mathrm{a}$ and $7 \mathrm{~b}$ for transient and stationary conditions, respectively. Note that for transient conditions the correction for $\mathrm{dE}_{\text {equi }} / \mathrm{dt}$ is small (see Eq. (2)) and is neglected. A scatter of the data points is clearly visible. There are different reasons for this scatter: (i) although it is possible to provoke I-mode behaviour, slight differences in the stored energy are found between the different scenarii; (ii) $P_{\text {tot }}$ can be overestimated in discharges with ICRH, since no correction is applied to the engineering value for boundary layer losses; (iii) for

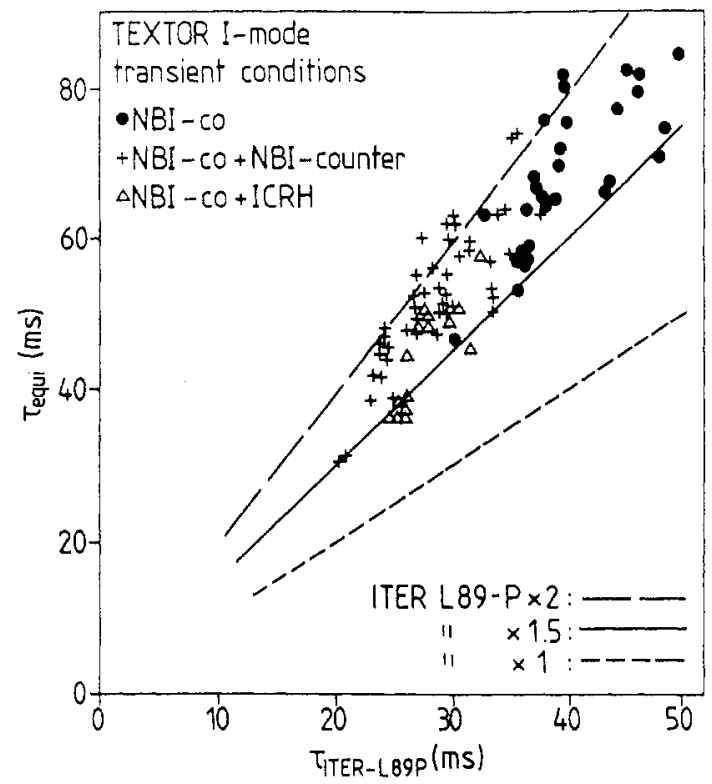

FIG. 7a. Comparison of the confinement time obtained in TEXTOR $I$-mode discharges under transient conditions with the predictions of $1,1.5$ and 2 times ITER L89-P. The data are taken from discharges with $200<I_{p}<500 \mathrm{kA}, 1.4<\bar{n}_{e 0}<2.6 \times 10^{13} \mathrm{~cm}^{-3}$ and $1.1<P_{\text {tot }}<3.0 \mathrm{MW}$. The NBI power is corrected for shinethrough and charge exchange losses.

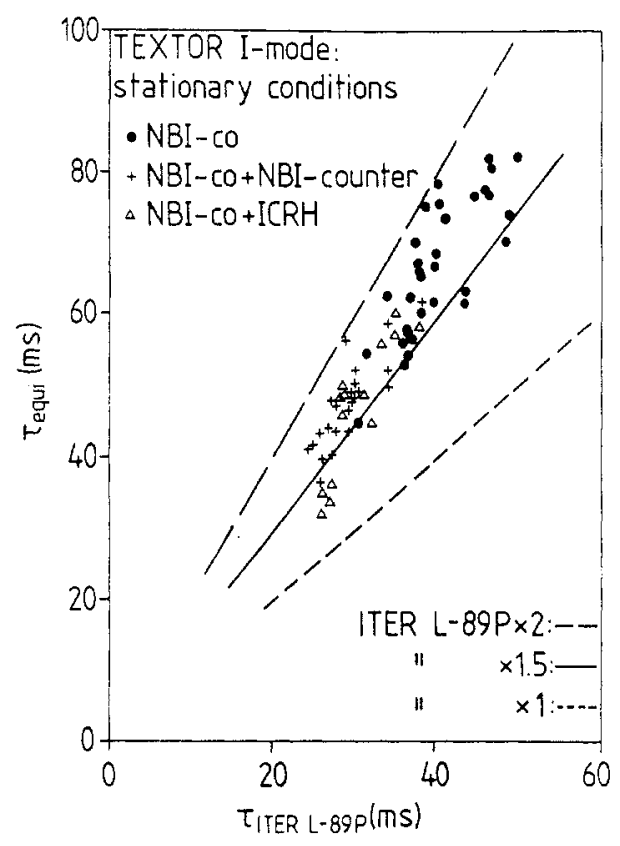

FIG. 7b. Comparison of the confinement time obtained in TEXTOR I-mode discharges under stationary conditions with the predictions of $1,1.5$ and 2 times ITER L89-P. The data are taken from discharges with $300<I_{p}<500 \mathrm{kA}, 1.8<\bar{n}_{e 0}<4.3 \times 10^{13} \mathrm{~cm}^{-3}$ and $1.5<P_{\text {tot }}<3.4 \mathrm{MW}$. The NBI power is corrected for shinethrough and charge exchange losses, as in Fig. $7 a$. 
TABLE I. ENHANCEMENT FACTOR WITH RESPECT TO ITER L89-P L-MODE SCALING OF THE ENERGY CONFINEMENT TIME OBTAINED IN TEXTOR I-MODE DISCHARGES

\begin{tabular}{l|c|c|c}
\hline & $E_{\text {equi }}$ & $E_{\text {dia }}$ & $E_{\text {kin }}$ \\
\hline Stationary & 1.68 & 1.43 & 1.14 \\
\hline Transient & 1.81 & 1.51 & \\
\hline
\end{tabular}

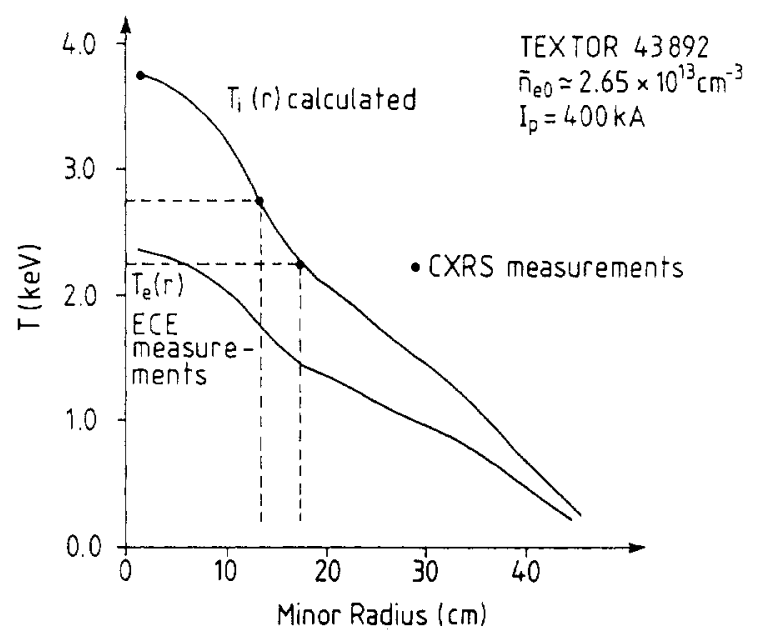

FIG. 8. Comparison of the ion temperature profile calculated by TRANSP, assuming $\chi_{i}=\chi_{e}$, with the data obtained from the CXRS diagnostic for the discharge shown in Fig. 2. Note the excellent agreement between the calculated and experimental values.

the set of discharges considered, there is a non-negligible effect of the plasma density, which shows up as a gradual confinement degradation for the total energy with increasing plasma density (see Section 4 for a detailed parametric study); (iv) the confinement scaling does not always follow a $\mathrm{P}_{\text {tot }}^{-0.5}$ dependence and often shows a linear offset type of behaviour.

For easy comparison, the predictions corresponding to $1,1.5$ and 2 times ITER L89-P have been added to the figure. Practically all data points are located between 1.5 and 2 times ITER L89-P. The mean value of the enhancement factor is 1.8 for transient conditions and 1.7 for stationary conditions. The same comparison can be made for $E_{\text {dia }}$ and $E_{\text {kin }}$. The results are summarized in Table I. If the engineering value for the injected beam power, $\mathrm{P}_{\mathrm{NI}}$, is applied, the values in this table are to be multiplied by 0.92 . Note that the values of the enhancement factor for transient conditions are approximately
$10 \%$ higher than those for stationary conditions, and that under stationary conditions a value corresponding to the ITER L89-P scaling is attained with the kinetic energy alone (see also the discussion of Figs 14a and 14b). We wish to stress that all the I-mode data points satisfy the selection criterion $E_{\text {fast }} / E_{\text {equi }} \leq 40 \%$ mentioned above. The mean value of $E_{\text {fast }} / E_{\text {equi }}$ in the dataset is about $25 \%$. We can therefore confidently compare the I-mode data with the data from $\mathrm{H}$-mode discharges obtained in other tokamaks (see also Ref. [8], especially p. 297-299).

Regarding the kinetic energy, the following comments can be made. $E_{k i n}$ is calculated by TRANSP from the experimental electron temperature and density profiles (measured at nine radial positions at least) and from the ion temperature profile. This last profile, however, is measured at only three radial positions. A complete ion temperature profile is therefore simulated with TRANSP, under the assumption $\chi_{\mathrm{i}}=\chi_{\mathrm{e}}$ or $\chi_{\mathrm{i}}=\frac{2}{3} \chi_{\mathrm{e}}$ at low densities. Good agreement with the measured data is obtained, as shown in Figs 4 and 8 .

A further comparison can be made with respect to H-mode discharges. In Fig. 9, the TEXTOR I-mode data points (obtained under stationary conditions) are added to the H-mode data compiled by the CIT physics study group [13]. The average $\mathrm{H}$-mode performance for the different tokamaks attains $(1.85 \pm 0.35) \tau_{\text {ITER L89-P }}$. The data from stationary TEXTOR I-mode discharges are indicated by the white domain, which represents the data cloud obtained. The TEXTOR I-mode data are well contained between the maximum and minimum $\mathrm{H}$-mode data boundaries in the figure, thus showing that the TEXTOR I-mode confinement data line up very well with the $\mathrm{H}$-mode results obtained in other machines.

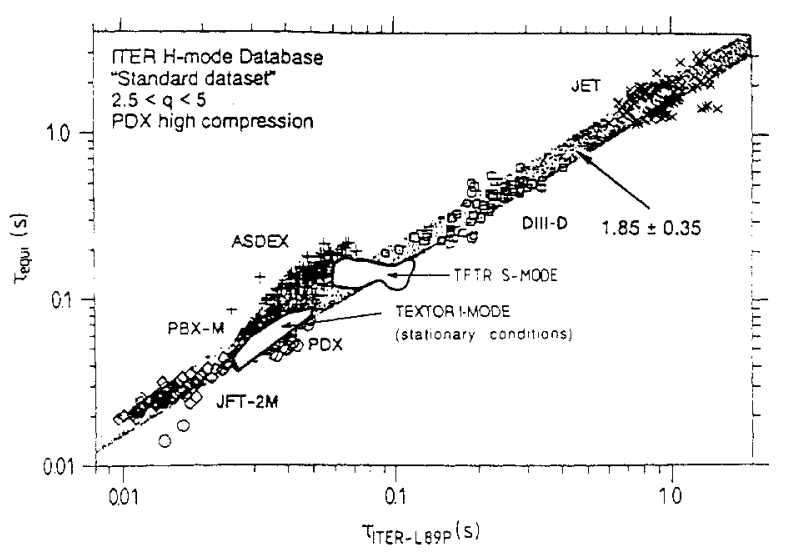

FIG. 9. Comparison of the confinement time of stationary TEXTOR I-mode discharges with that of the ITER H-mode database. 


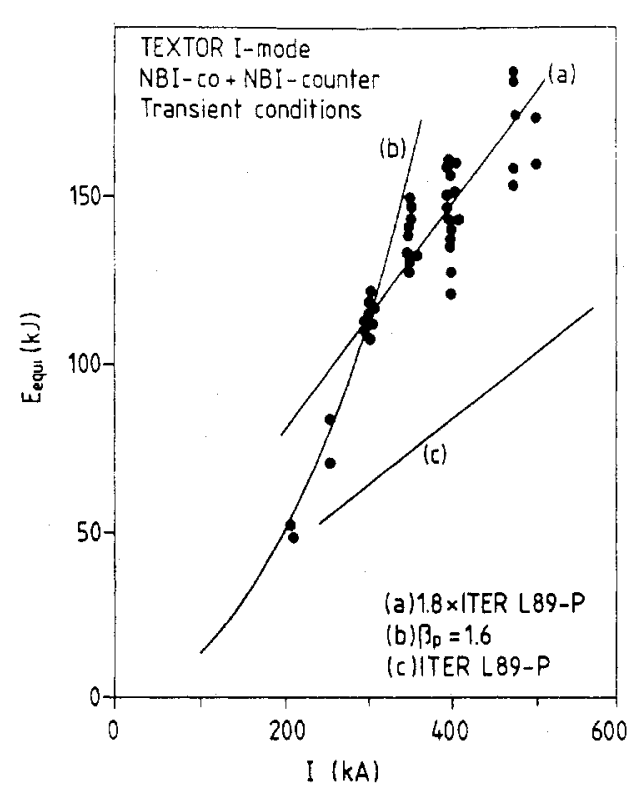

FIG. 10. Current scaling of the equilibrium (or MHD) energy values from transient 1-mode discharges. Curves (a) and (c) show the predictions of $1.8 \times$ ITER L89-P and ITER L89-P, respectively, and curve (b) gives the equilibrium energy values corresponding to $\beta_{p \text {, equi }}=1.6$. The data are taken from discharges corresponding to $1.6<\bar{n}_{e O}<3.2 \times 10^{13} \mathrm{~cm}^{-3}$ and $2.5<P_{t o t}<3.1 \mathrm{MW}$.

A more recent analysis of confinement data obtained for a mixture of ELMy and ELM-free H-mode discharges on many different machines results in an average $\mathrm{H}$-mode enhancement factor of 2.11 with respect to ITER L89-P [8]. For data obtained on ASDEX, DIII-D and JFT-2M, the enhancement factor is 2.13 (mostly ELMy H-mode data), 1.74 (mostly ELMy H-mode data) and 1.63 (mostly ELM-free H-mode data) for the respective machines; for TFTR supershots the enhancement factor is 1.9 .

The enhancement factor 1.68 , obtained in stationary TEXTOR I-mode discharges, thus compares very well with the results obtained in $\mathrm{H}$-mode discharges on DIII-D and JFT-2M, but is somewhat less favourable with respect to ASDEX. A detailed discussion of the comparison with ELMy and ELM-free ASDEX H-mode discharges is given in Section 5 .

\section{DETAILED PARAMETER DEPENDENCE}

\subsection{Current scaling and beta limits}

The current scaling of the I-mode discharges is illustrated in Fig. 10, which shows the equilibrium energy as a function of the total plasma current for transient

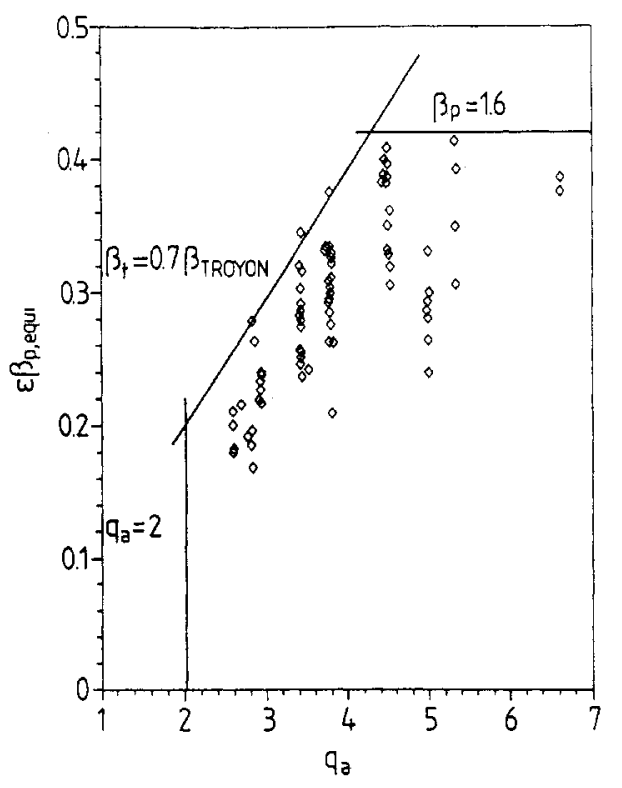

FIG. 11. Values of $\epsilon \beta_{p}$ as a function of $q_{a}$, as obtained in I-mode discharges. The lines correspond to $\beta_{p}=1.6, \beta_{t}=0.7 \beta_{\text {Troyon }}$ and $q_{a}=2$. The data are taken from discharges at $205<I_{p}<530 \mathrm{kA}$, $1.44<\bar{n}_{e 0}<4.54 \times 10^{13} \mathrm{~cm}^{-3}$ and $1.6<P_{t o t}<3.9 \mathrm{MW}$.

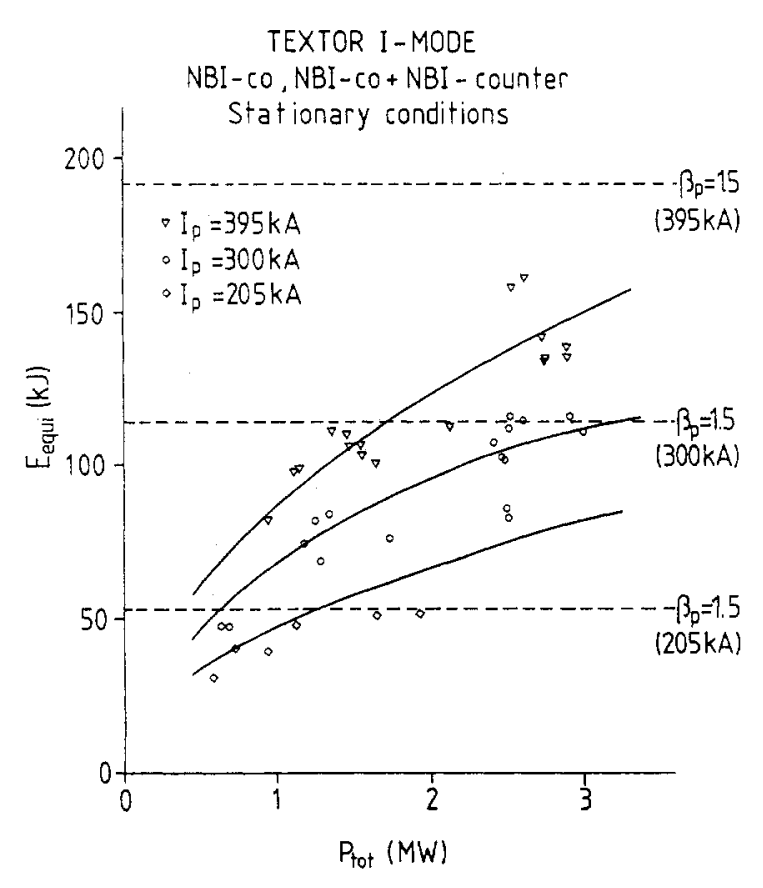

FIG. 12. Power scaling of the equilibrium (or MHD) energy obtained in TEXTOR $I$-mode discharges at $I_{p}=205,300$ and $395 \mathrm{kA}$, and $1.5<\bar{n}_{e 0}<3.1 \times 10^{13} \mathrm{~cm}^{-3}$. The full lines correspond to $1.8 \times$ ITER L89-P and the dashed lines give the equilibrium energy values corresponding to $\beta_{p, \text { equi }}=1.5$ for the respective currents. 
conditions. The predictions of ITER L89-P are shown by curve (c). Curve (a) shows the predictions of $1.8 \times$ ITER L89-P, whereas curve (b) shows the equilibrium energy values corresponding to $\beta_{\mathrm{p} \text {, equi }}=1.6$.

There is a marked difference in the behaviour of points corresponding to plasma currents below $300 \mathrm{kA}$ and above $300 \mathrm{kA}$. The latter scale roughly as $1.8 \times$ ITER L89-P and are thus well above the L-mode scaling. The points for a plasma current below $300 \mathrm{kA}$ are located systematically below this curve, although they are still somewhat above the L-mode scaling. They do not exceed the $\beta_{\mathrm{p} \text {, equi }}=1.6$ line which appears to be an experimental beta limit for TEXTOR. This limit is already reached for $P_{\text {tot }}=1.7 \mathrm{MW}$ at $I_{p}=205 \mathrm{kA}$ and for $\mathrm{P}_{\text {tot }}=3.5 \mathrm{MW}$ at $\mathrm{I}_{\mathrm{p}}=300 \mathrm{kA}$.

The best toroidal beta values obtained in I-mode discharges almost reach $\beta_{t}=1.0 \%$, corresponding to 0.7 times the Troyon limit, defined as $2.8 \mathrm{I}_{\mathrm{p}} /\left(\mathrm{aB}_{\mathrm{t}}\right)$.

In Fig. 11, the loci of I-mode discharges are given in an $\epsilon \beta_{\mathrm{p}}=\mathrm{f}\left(\mathrm{q}_{\mathrm{a}}\right)$ diagram, with $\epsilon=\mathrm{a} / \mathrm{R}$. The $\beta_{\mathrm{t}}$ and $\beta_{p}$ limits given above, together with $q_{a}=2$, form the boundaries of the data cloud obtained.

\subsection{Power scaling}

The power scaling of TEXTOR I-mode data at different plasma currents is shown in Fig. 12, where $E_{\text {equi }}$ is given as a function of the total net heating power $P_{\text {tot }}$. The data points roughly fit the full lines, which show the predictions of $1.8 \times$ ITER L89-P for the three plasma currents considered.

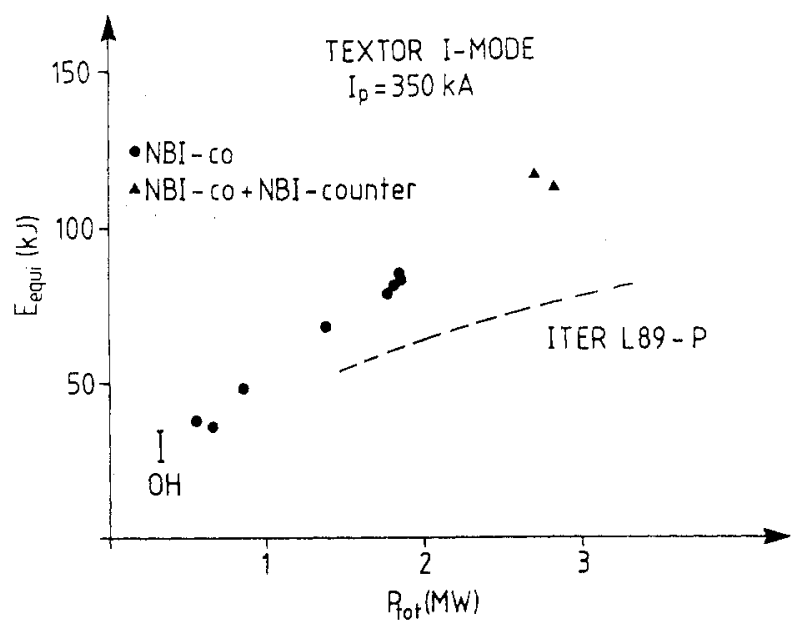

FIG. 13. Scaling of the equilibrium energy with the net heating power for successive TEXTOR I-mode discharges at $I_{p}=350 \mathrm{kA}$ and $2.75<\bar{n}_{e 0}<3.70 \times 10^{13} \mathrm{~cm}^{-3}$. No power threshold is seen in going from ohmically heated to additionally heated TEXTOR I-mode discharges.
A saturation of $E_{\text {equi }}$ is clearly visible in Fig. 12 for a plasma current $I_{p}=205 \mathrm{kA}$ at $P_{\text {tot }}>1.5 \mathrm{MW}$. This saturation is not visible at $I_{p}=300$ and $395 \mathrm{kA}$, because in these cases $P_{\text {tot }}$ was not sufficient to exceed the $\beta_{\mathrm{p} \text {, equi }}=1.5$ limit, indicated by the horizontal dashed curves for the respective currents. This limit is lower than the previously mentioned beta limit, because it is obtained in stationary discharges. At $300 \mathrm{kA}$ and $P_{\text {tot }}=3.5 \mathrm{MW}$, this beta limit is just reached.

Figure 13 shows the results of a power scan for the equilibrium energy, starting from $\mathrm{OH}$ conditions, for a series of successive Ohmic and NBI-co and NBI-co + NBI-counter heated I-mode discharges with the same wall conditioning. No power threshold is found and the data show a linear offset type behaviour, in contrast with the $\mathrm{P}_{\text {tot }}^{-0.5}$ dependence of the ITER L89-P scaling law. The fact that, globally, the scaling appears to be retrieved in Fig. 12 has to do with the fact that points from very different conditions are brought together in this figure.

\subsection{Density scaling}

Whereas the functional dependences of the ITER L89-P scaling on $I_{p}$ and $P_{\text {tot }}$ are approximately retrieved, marked differences are found for the density scaling. Figure $14 \mathrm{a}$ shows the evolution of $\mathrm{E}_{\text {equi }}, \mathrm{E}_{\mathrm{dia}}$, $E_{k i n}$ and $E_{e}$ as a function of $\bar{n}_{e 0}$ for I-mode discharges heated with NBI-co alone. Note that discharges with $\bar{n}_{\mathrm{e} 0} \geq 2 \times 10^{13} \mathrm{~cm}^{-3}$ satisfy the condition $E_{\text {fast }} / E_{\text {equi }}$ $\leq 40 \%$ and that $E_{e}$ is roughly half of $E_{k i n}$. It is clearly seen that $E_{\text {equi }}$ decreases with increasing density, in contrast to the $\overline{\mathrm{n}}_{\mathrm{e} 0}^{0.1}$ dependence of the ITER L89-P scaling. With increasing density, $E_{\text {equi }}$ and $E_{\text {dia }}$ tend to reach the same asymptotic value as $E_{\text {kin }}$, which is roughly equal to $85 \mathrm{~kJ}$ for this case, indicating that the plasma becomes more and more Maxwellian, owing to a decreased suprathermal plasma particle population at high densities. Also indicated in this figure are the predictions of ITER L89-P, using in the calculation of $P_{\text {tot }}$ the corrected value $P_{\mathrm{NI} \text {, corr }}$ (indicated by the full line) and the engineering value $\mathrm{P}_{\mathrm{NI}}$ (indicated by the dashed line). It is seen that $E_{\text {kin }}$ roughly scales as ITER L89-P.

Figure $14 \mathrm{~b}$ is a similar plot for the case of balanced NBI-co + NBI-counter-injection. The engineering value $\mathrm{P}_{\mathrm{NI}-\mathrm{co}}+\mathrm{P}_{\mathrm{NI}-\mathrm{counter}}$ in this case is twice the engineering value $\mathrm{P}_{\mathrm{NI}-\mathrm{co}}$ in Fig. 14a. Note that in spite of the larger scatter of the results, the same trends are seen as in Fig. 14a, with the asymptotic value at high density for $E_{\text {equi }}, E_{\text {dia }}$ and $E_{\text {kin }}$ being roughly equal to $\sqrt{2}$ times the 


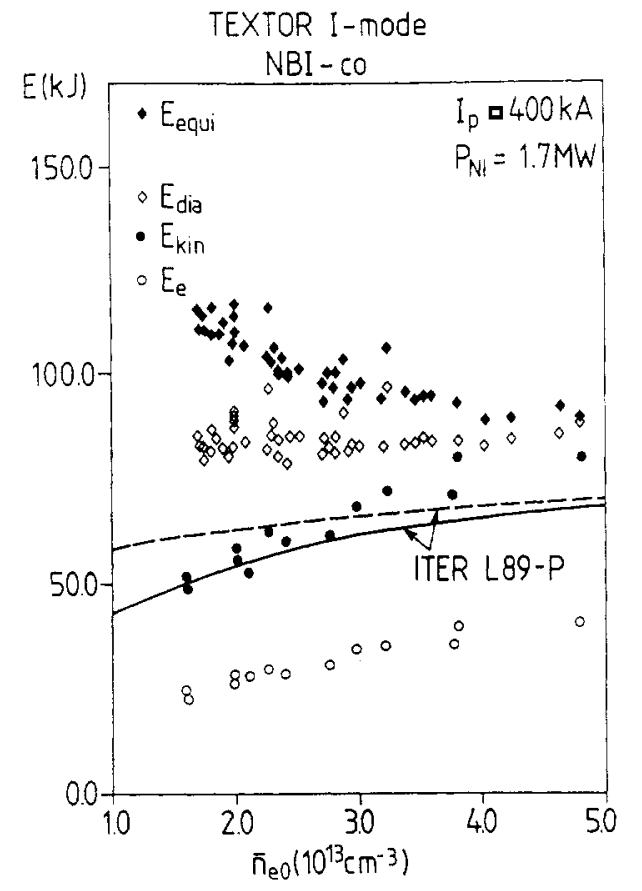

FIG. 14a. Evolution of different plasma energies as a function of the central line averaged electron density for TEXTOR I-mode discharges obtained with NBI-co heating alone, at a plasma current $I_{p}=400 \mathrm{kA}$ and an engineering value of the injected beam power $P_{\text {NI-co }}=1.7 \mathrm{MW}$. The predictions of ITER L89-P are given using $P_{N l}$, the engineering value of the beam power (dashed line), and $P_{N I, \text { corr }}$, the beam power corrected for shinethrough and charge exchange (full line).

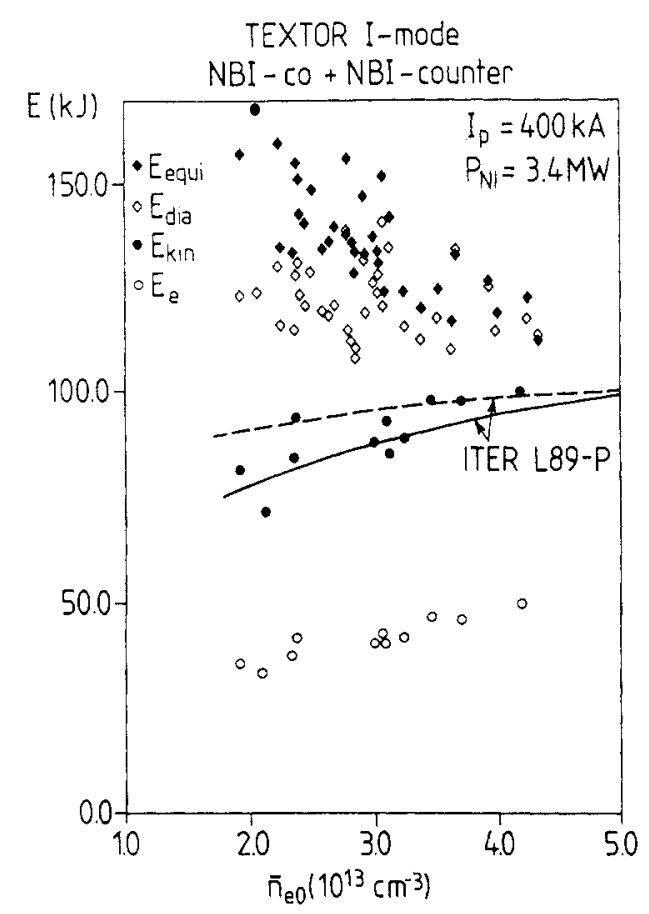

FIG. 14b. Evolution of different plasma energies as a function of the central line averaged electron density for TEXTOR I-mode discharges with NBI-co $+N B I$-counter heating, at a plasma current $I_{p}=400 \mathrm{kA}$ and an engineering value of the injected beam power $P_{\text {NI-co }}+P_{\text {NI-counter }}=3.4 \mathrm{MW}$. The predictions of ITER L89-P are given using $P_{N 1}$, the engineering value of the beam power (dashed line), and $P_{N I, \text { corr }}$, the beam power corrected for shinethrough and charge exchange (full line).

TABLE II. COMPARISON OF EXPERIMENTAL VALUES OF $E_{\text {equi }}$ (assuming $\ell_{\mathrm{i}}=$ const) AND $\mathrm{E}_{\mathrm{dia}}$ WITH THOSE OBTAINED FROM TRANSP*

\begin{tabular}{l|c|c|c|c|c|c|c|c|c}
\hline Shot & Heating & $\overrightarrow{\mathrm{n}}_{\mathrm{e} 0}$ & $\mathrm{E}_{\mathrm{kin}}$ & $\begin{array}{c}\mathrm{E}_{\mathrm{dia}} \\
\mathrm{TRANSP} \\
\left(10^{13} \mathrm{~cm}^{-3}\right)\end{array}$ & $\begin{array}{c}\mathrm{E}_{\text {equi }} \\
\mathrm{TR} \text { (kJ) } \\
(\mathrm{kJ})\end{array}$ & $\begin{array}{c}\mathrm{E}_{\mathrm{dia}} \\
(\mathrm{kJ})\end{array}$ & $\begin{array}{c}\mathrm{E}_{\text {equi }} \\
(\mathrm{kJ})\end{array}$ & $\begin{array}{c}\ell_{\mathrm{i}} / 2 \\
\text { TRANSP } \\
\text { Ohmic heating phase }\end{array}$ & $\begin{array}{c}\ell_{\mathrm{i}} / 2 \\
\text { TRANSP } \\
\text { Add. heating phase }\end{array}$ \\
\hline 44493 & Co-injection & 1.6 & 51 & 81 & 121 & 88 & 118 & 0.70 & 0.73 \\
\hline 45951 & Co-injection & 3.0 & 68 & 79.5 & 93.5 & 80 & 89.5 & 0.67 & 0.64 \\
\hline 46856 & Co-injection & 4.8 & 80 & 88 & 97 & 88 & 88 & 0.64 & 0.61 \\
\hline 44566 & Co- + counter-injection & 2.1 & 75 & 128 & 176 & 122 & 162 & 0.705 & 0.68 \\
\hline 45562 & Co- + counter-injection & 4.2 & 100 & 118 & 136 & 114 & 120 & 0.63 & 0.64 \\
\hline
\end{tabular}

* In addition, the difference in $\ell_{\mathrm{i}}$ between the Ohmic phase and the beam heated phase as given by TRANSP is shown. 


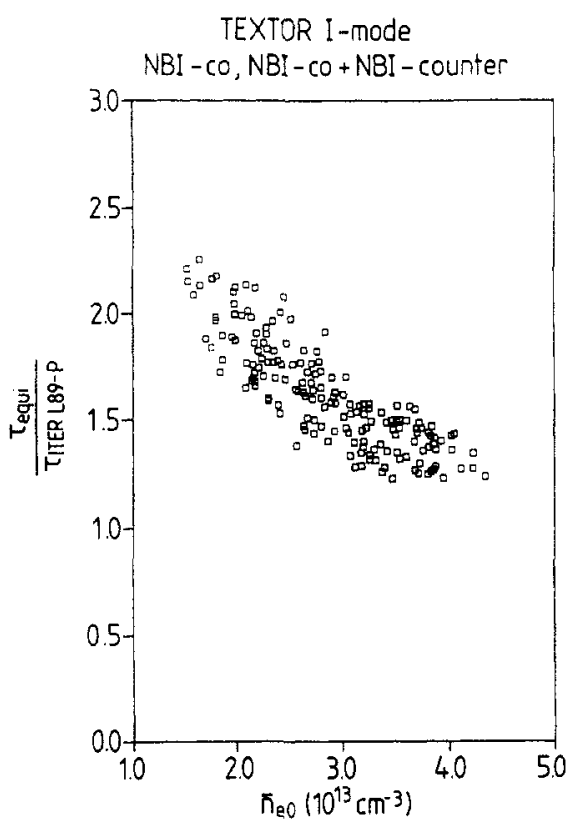

FIG. 15. Variation of the enhancement of the confinement time with respect to ITER $L-89 P$ as a function of the line averaged central density in TEXTOR I-mode discharges. The data are taken from discharges with $280<I_{p}<530 \mathrm{kA}$ and $1.6<P_{t o t}<3.6 \mathrm{MW}$.

asymptotic value for pure NBI-co-injection. The more $\overline{\mathrm{n}}_{\mathrm{e} 0}$ exceeds $4 \times 10^{13} \mathrm{~cm}^{-3}$, the higher is the number of discharges with energy values lower than this asymptotic value, and, in some cases, there are energy values that are marginally higher than those for pure NBI-co heated discharges. Such discharges pertain to L-mode scaling and are not considered in this study; their behaviour seems to be linked with recycling (see Section 6). Table II presents a comparison of typical experimental values of $E_{\text {dia }}$ or $E_{\text {equi }}$, as shown in Fig. 14a, with those calculated with the help of TRANSP. The values obtained with TRANSP are in general somewhat higher than the experimental ones; this is partly due to the small change in $\ell_{i}$, as discussed in Section 2.

The data in Figs 14a and 14b could be somewhat influenced by the change in the beam power deposition profile with density because no correction for this effect has been taken into account.

When the enhancement factor of $\tau_{\text {equi }}$ with respect to the predictions of ITER L89-P is plotted as a function of the line averaged central electron density (Fig. 15), an even more important $\overline{\mathrm{n}}_{\mathrm{e} 0}$ dependence than in Figs $14 \mathrm{a}$ and $14 \mathrm{~b}$ is obtained; this is due to the increase in the net heating power $P_{\text {tot }}$ with increasing $\bar{n}_{\mathrm{e} 0}$ in the ITER L89-P scaling law. The enhancement factor decreases with increasing density, being 2.3 at low density $\left(\overline{\mathrm{n}}_{\mathrm{e} 0} \cong 1.5 \times 10^{13} \mathrm{~cm}^{-3}\right)$ and approximately 1.25 at high density $\left(\overline{\mathrm{n}}_{\mathrm{e} 0} \cong 4.5 \times 10^{13} \mathrm{~cm}^{-3}\right)$. Note that a similar density dependence is also observed in H-mode discharges on the DIII-D tokamak [14].

The reason for this behaviour can be understood as follows: (i) for a given constant engineering value of the beam power, the net injected power increases with density owing to the decrease of the charge exchange and shinethrough losses; thus, we would expect an asymptotic curve for the energies that increases with increasing density; (ii) this is, however, counteracted by the flattening of the deposition profile for the beam power and probably cancels the preceding effect; (iii) then, the decrease of $E_{\text {equi }}$ due to the decrease of the contribution of suprathermal particles, as discussed above, together with the increase in the energy values with density predicted by ITER L89-P (proportional to $\left.\overline{\mathrm{n}}_{\mathrm{e} 0}^{0.1} \mathrm{P}_{\mathrm{tot}}^{0.5}\right)$ leads to a reduction of the enhancement factor $\mathrm{E}_{\text {equi }} /\left(\mathrm{P}_{\text {tot }} \tau_{\text {ITER L89-p }}\right)$ with increasing densities.

The case of I-mode discharges obtained with combined ICRH + NBI-co heating has already been discussed by Messiaen et al. (Fig. 9a of Ref. [1]). The largest difference with respect to purely beam heated I-mode discharges is seen in the ratio of the perpendicular to the parallel anisotropic tail components. The energies show an enhanced contribution of the perpendicular energy of the fast particles, $E_{\perp, a}$; at an ICRH power level comparable to the applied NBI-co power, this can lead to a seemingly isotropic tail distribution $\left(2 \mathrm{E}_{\|, \mathrm{a}}=\mathrm{E}_{\perp, \mathrm{a}}\right)$.

\section{COMPARISON OF THE CHARACTERISTICS OF THE I-MODE WITH THOSE OF OTHER ENHANCED CONFINEMENT REGIMES}

\subsection{Comparison with the $\mathrm{H}$-mode in a divertor machine of similar size [15]}

Figure 16 shows typical electron density and temperature profiles obtained during the Ohmic phase and the I-mode phase of a TEXTOR discharge (\#45726). Similar profiles are shown in Fig. 17, obtained in an ELMy H-mode discharge on ASDEX (\#29861; period of the ELMs $\tau_{\text {ELMs }}=5 \mathrm{~ms}$ ). The discharges on the two machines have nearly the same plasma conditions during the auxiliary heating phase (see Table III).

The similarity of the electron temperature and density profiles in the two machines is apparent, although a direct comparison is difficult: (i) since the profiles in TEXTOR are measured along a horizontal chord and 


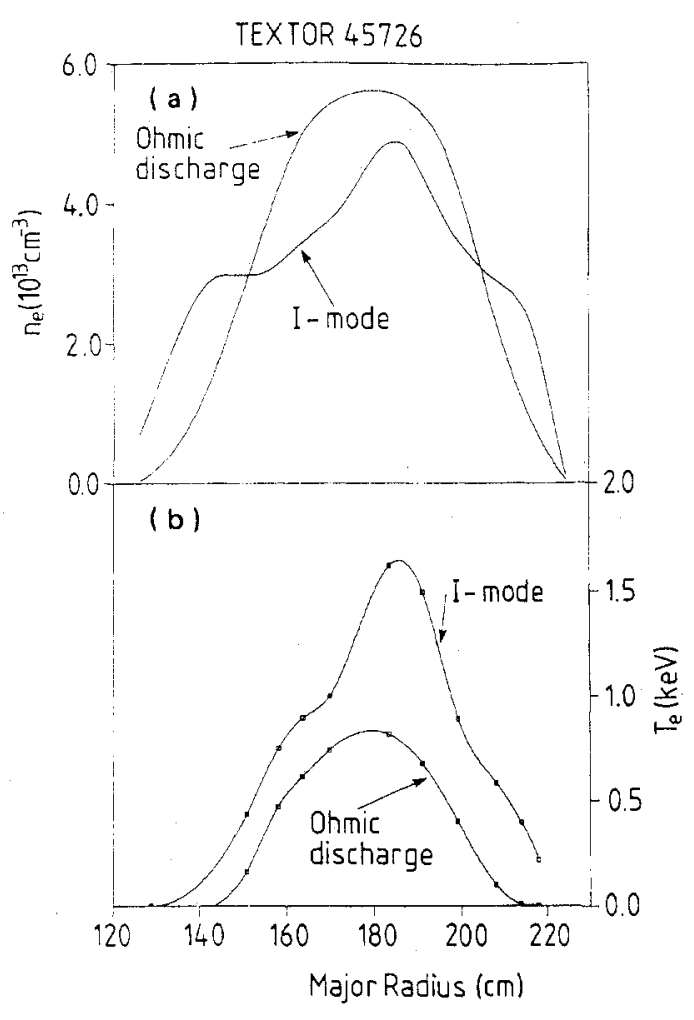

FIG. 16. Radial profiles of (a) $n_{e}$ and (b) $T_{e}$ during the Ohmic and I-mode phases of TEXTOR discharge $\$ 45726$.

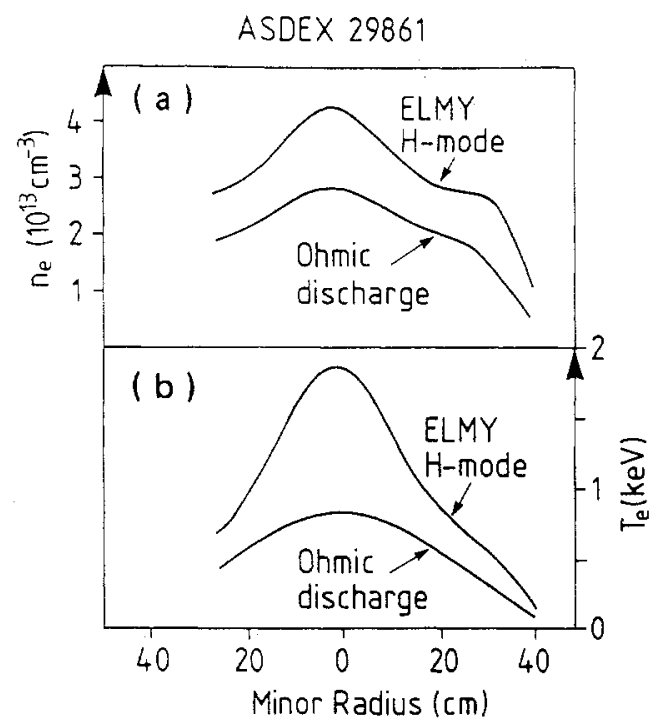

FIG. 17. Radial profiles of (a) $n_{e}$ and (b) $T_{e}$ during the Ohmic and ELMy H-mode phases $\left(\tau_{E L M s}=5 \mathrm{~ms}\right)$ of ASDEX discharge $\# 29861$. those in ASDEX are measured along a vertical chord, a Shafranov shift is visible in the profiles from TEXTOR, but not in those from ASDEX; (ii) the plasma radius is somewhat different for the two machines. Nevertheless, the strong peaking of the profiles obtained during the TEXTOR I-mode is clearly visible and is very similar to the observed peaking of the ASDEX profiles. In addition to the peaking, large edge pedestals develop in TEXTOR near the limiter. These features are seen in more detail in Fig. 18, showing the electron density and temperature in the plasma edge $(r=42-48 \mathrm{~cm})$ as measured with lithium and helium beam probing techniques [16] for a TEXTOR discharge (\#47632) with similar parameters as the discharge in Fig. 16. The electron density and temperature profiles steepen strongly in the vicinity of the limiter during the I-mode. At the same line density, the electron density values at $\mathrm{r} / \mathrm{a}=0.9$ are approximately the same $\left(\cong 2 \times 10^{13} \mathrm{~cm}^{-3}\right)$ for the ASDEX divertor $\mathrm{H}$-mode and the TEXTOR I-mode. The electron temperature values at the same position are also similar $(\cong 300 \mathrm{eV})$.

The confinement characteristics of the two discharges are also compared in Table III, which shows almost identical energy content and confinement times. Note that only the diamagnetic energy values are listed for this comparison, since they are the only plasma energy values available for the ASDEX discharges. Regarding the L-mode scaling law, ASDEX performs somewhat better than TEXTOR (of the order of 20-25\%) because of the larger size of TEXTOR $(R=1.75 \mathrm{~m}$ for TEXTOR and $\mathrm{R}=1.65 \mathrm{~m}$ for ASDEX; $\mathrm{a}=0.46 \mathrm{~m}$ for TEXTOR and $\mathrm{a}=0.4 \mathrm{~m}$ for ASDEX) and the difference in plasma composition (mean atomic mass $A_{i}=2$ for TEXTOR and $A_{i}=1.5$ for ASDEX).

Further entries in Table III pertain to non-stationary discharges: an ELM-free discharge in ASDEX ( $\# 29873$ ) to be compared with a TEXTOR I-mode discharge under transient conditions (\#43750), both lasting $150 \mathrm{~ms}$. The diamagnetic energy shows an enhancement factor with respect to ITER L89-P of 1.72 for TEXTOR and of 2.26 for ASDEX.

\subsection{Comparison with the supershot regime [17]}

In the case of combined NBI-co + NBI-counter heating, the TEXTOR I-mode data show similarities with the supershot or S-mode regime found in TFTR. The S-mode regime, obtained with balanced NBI-co + NBI-counter-injection, is characterized by an enhanced confinement up to four times L-mode confinement and by peaked profiles of the electron temperature and density. Figure 19 shows a typical example of these 
IMPROVED CONFINEMENT IN TEXTOR

TABLE III. COMPARISON OF THE CONFINEMENT PROPERTIES OF ELM-FREE AND ELMY H-MODE DISCHARGES AND TEXTOR I-MODE DISCHARGES

\begin{tabular}{|c|c|c|c|c|}
\hline & \multicolumn{2}{|c|}{ ASDEX } & \multicolumn{2}{|c|}{ TEXTOR } \\
\hline & $\begin{array}{l}\text { No. } 29861 \\
\tau_{\mathrm{ELMs}}=5 \mathrm{~ms}\end{array}$ & $\begin{array}{l}\text { No. } 29873 \\
\text { ELM-free }\end{array}$ & $\begin{array}{l}\text { No. } 45726 \\
\text { Stationary }\end{array}$ & $\begin{array}{l}\text { No. } 43750 \\
\text { Transient }\end{array}$ \\
\hline$B_{t}[T]$ & 1.9 & 1.9 & 2.35 & 2.25 \\
\hline$I_{p}[\mathrm{kA}]$ & 280 & 280 & 280 & 300 \\
\hline$\overline{\mathrm{n}}_{\mathrm{e} 0}\left[10^{13} \mathrm{~cm}^{-3}\right]$ & 3.0 & 3.9 & 3.1 & 3.0 \\
\hline$P_{N I}[M W]$ & 2.6 & 2.6 & 2.6 & 3.1 \\
\hline$P_{\text {tot }}[\mathrm{MW}]$ & 2.02 & 2.15 & 2.3 & 2.65 \\
\hline$E_{\text {dia }}[\mathrm{kJ}]$ & 73 & 93 & 78 & 114 \\
\hline$\tau_{\text {dia }}[\mathrm{ms}]$ & 36 & 43 & 34 & 43 \\
\hline$\tau_{\text {ITER L89-P }}[\mathrm{ms}]$ & $20\left(A_{i}=1.5\right)$ & $19\left(A_{i}=1.5\right)$ & $24\left(A_{j}=2.0\right)$ & $25\left(A_{i}=2.0\right)$ \\
\hline$\frac{\tau_{\text {dia }}}{\tau_{\text {ITER L89-P }}}$ & 1.8 & 2.26 & 1.41 & 1.72 \\
\hline
\end{tabular}

profiles during a supershot. The similarity with the TEXTOR I-mode profiles as given in Fig. 16 is striking.

The confinement in supershots is linked with the density profile peaking factor $\gamma_{\mathrm{n}}$ (defined as $\hat{\mathrm{n}}_{\mathrm{e}} /\left\langle\mathrm{n}_{\mathrm{e}}(\mathrm{r})\right\rangle$, where $\hat{n}_{e}$ is the peak value of the electron density profile and $\left\langle n_{e}(r)\right\rangle$ is the volume average of the electron

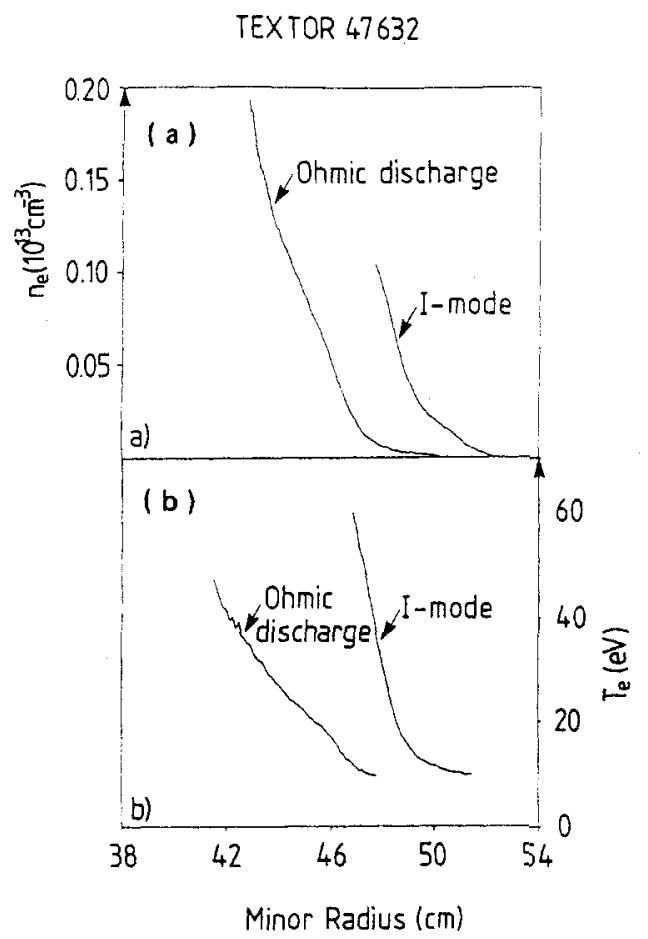

FIG. 18. Edge radial profiles of (a) $n_{e}$ and (b) $T_{e}$ during the Ohmic and I-mode phases of TEXTOR discharge $\$ 47632$.

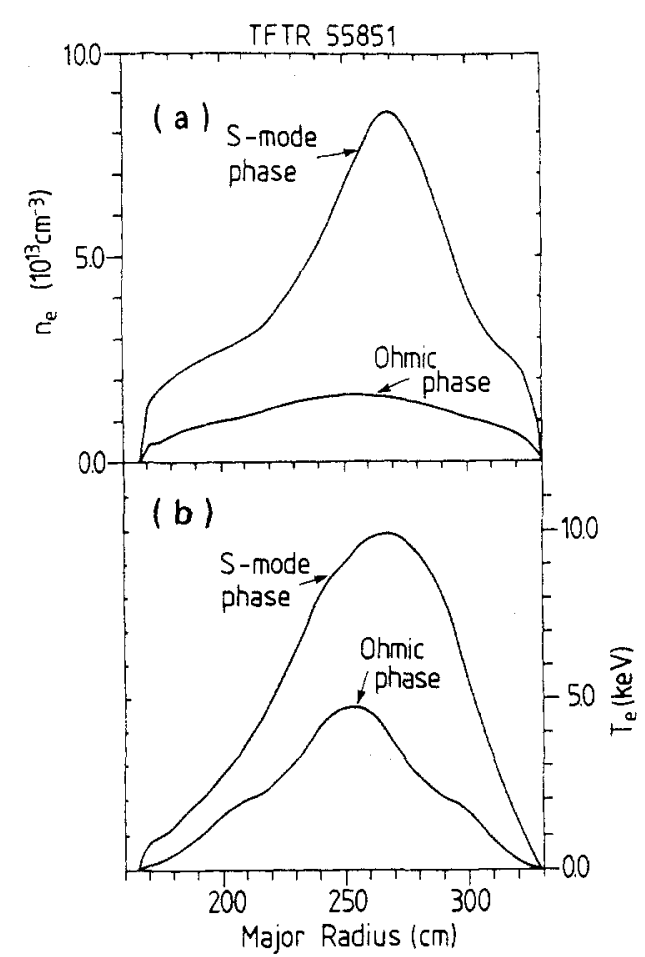

FIG. 19. Radial profiles of (a) $n_{e}$ and (b) $T_{e}$ during the Ohmic and supershot phases of TFTR discharge \#55851.

density [18]). Figure 20a shows the evolution of the confinement enhancement over ITER L89-P as a function of $\gamma_{\mathrm{n}}$ for TEXTOR I-mode discharges heated with NBI-co + NBI-counter-injection. A correlation between the two parameters can be seen. An equally strong correlation exists between the density profile peaking 


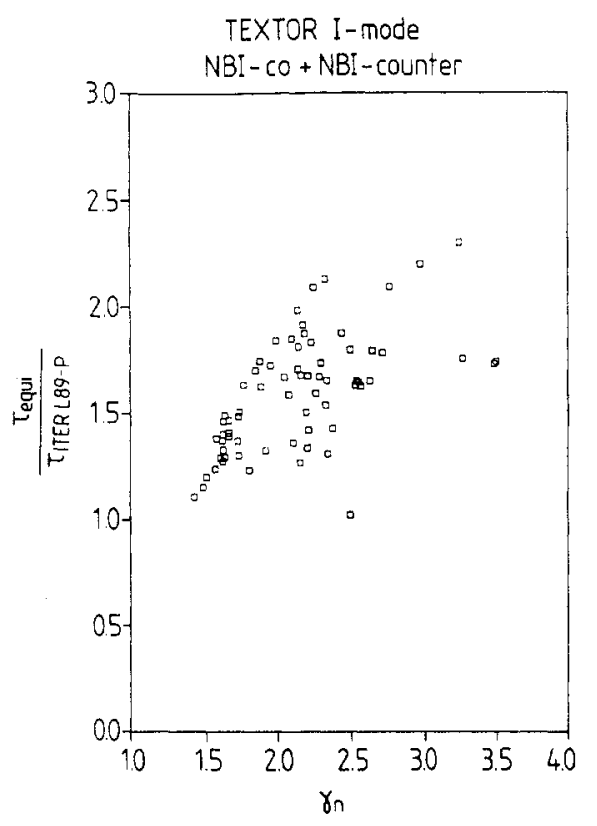

FIG. 20a. Relationship between the enhancement of the confinement time over ITER L89-P and the density profile peaking factor $\gamma_{n}=\hat{n}_{e} /\left\langle n_{e}(r)\right\rangle$, for TEXTOR I-mode discharges heated with NBI-co $+N B I$-counter. The data are taken from discharges at $280<I_{p}<530 \mathrm{kA}, 2.1<\bar{n}_{e 0}<4.2 \times 10^{13} \mathrm{~cm}^{-3}$ and $2.5<P_{t o t}<3.9 \mathrm{MW}$.

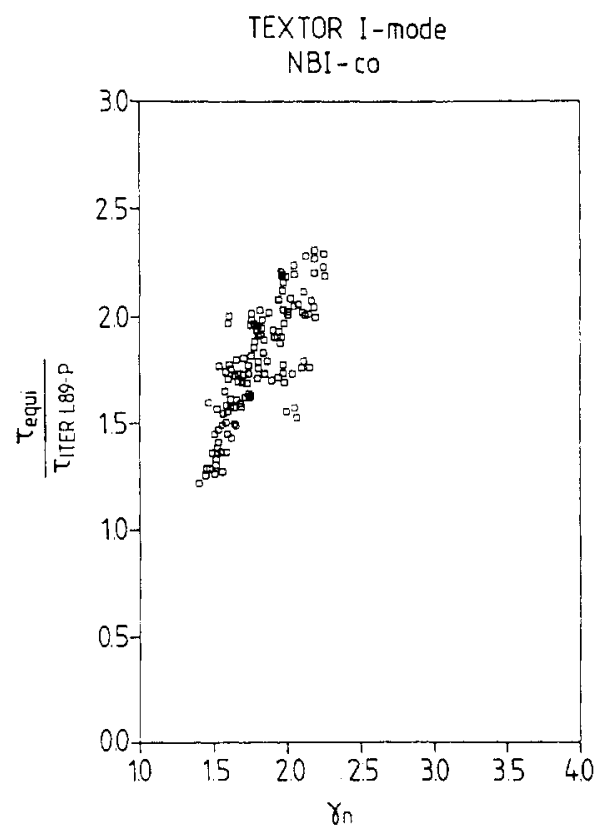

FIG. 20b. Same as Fig. 20a, but in this case for TEXTOR I-mode discharges heated with NBI-co alone. The data are taken from discharges at $205<I_{p}<530 \mathrm{kA}, 1.5<\bar{n}_{e 0}<4.62 \times 10^{13} \mathrm{~cm}^{-3}$ and $1.6<P_{10 t}<2.0 \mathrm{MW}$.

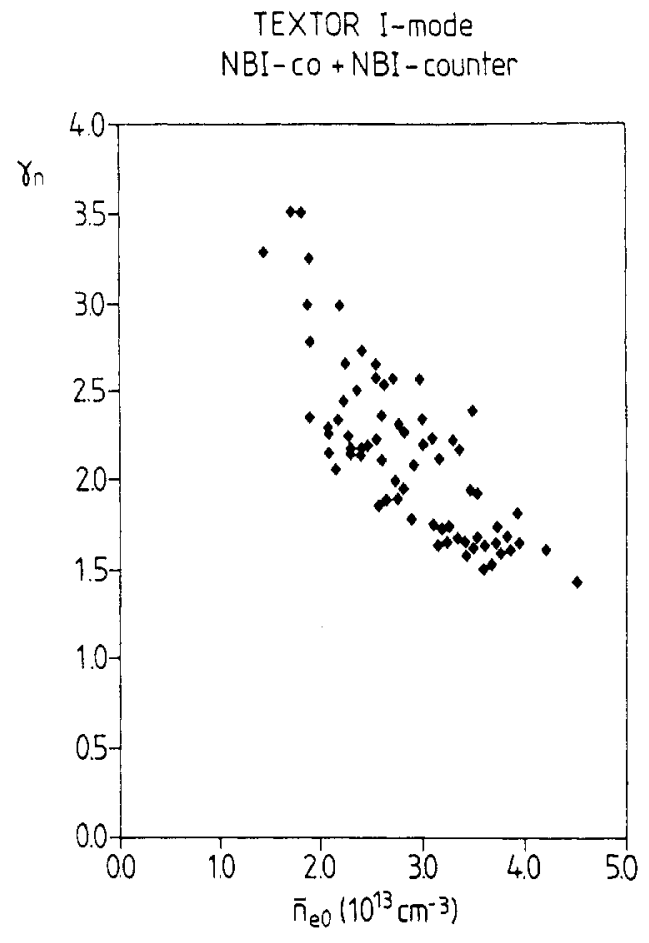

FIG. 21. Variation of the density profile peaking factor $\gamma_{n}=\hat{n}_{e} /\left\langle n_{e}(r)\right\rangle$ with the plasma density for I-mode discharges obtained with NBI-co + NBI-counter heating. Data are taken from discharges at $205<I_{p}<530 \mathrm{kA}$ and $1.6<P_{t o t}<3.9 \mathrm{MW}$.

factor and the line averaged central density, as shown in Fig. 21.

For comparison, we give the results obtained for TEXTOR I-mode discharges heated only with NBIco-injection. Figure 20b shows the behaviour of the enhancement factor as a function of $\gamma_{\mathrm{n}}$. We note that the maximum confinement enhancement for this case is the same as that for the case of I-mode discharges heated with NBI-co + NBI-counter-injection, although the peaking factor $\gamma_{\mathrm{n}}$ does not reach the same high values as in the case of NBI-co + NBI-counter heating. This suggests that the peaking of the electron density profile is not the only factor determining the confinement.

Other similarities with the supershot regime are: (i) Supershots occur in a particular region of the $\epsilon \beta_{\mathrm{p}}=\mathrm{f}\left(\mathrm{q}_{\mathrm{a}}\right)$ diagram [19] limited by a $\beta_{\mathrm{p}}$ limit ( $\sim 2-2.2$ for TFTR and $\sim 1.5-1.6$ for TEXTOR), as shown in Fig. 11; (ii) $\chi_{\mathrm{i}} \cong \chi_{\mathrm{e}}$ (see Section 3 ) is also found for supershots [20]; (iii) as for supershots, the current profile in TEXTOR tends to broaden in I-mode discharges with respect to Ohmic discharges [20]; (iv) there is a decrease of the peaking factor with increasing densities [21]; and (v) there is a loss of confinement in the presence of MHD activity $[19,20]$. 


\section{CONDITIONS FOR THE TEXTOR I-MODE}

Although it is not yet clear what the exact conditions for setting up the I-mode are, it seems that two necessary conditions are low recycling and the absence of MHD activity.

\subsection{Role of MHD activities}

As mentioned earlier, a transition from the I-regime to a regime with lower confinement is sometimes seen. An example of such a transition is shown in Fig. 22 (TEXTOR discharge \#44566). The first $100-150 \mathrm{~ms}$ of the additional heating phase correspond to I-mode behaviour. After this time interval, there is a sudden drop of the energies, the electron temperature and the neutron yield. This drop is not due to an increase in the impurities in the centre of the discharge, as shown by the impurity lines Fe XX and Fe XXI. The transition is accompanied by strong MHD activity, as illustrated in Fig. 23, which shows another TEXTOR discharge ( \#45946) with very similar plasma parameters. MHD

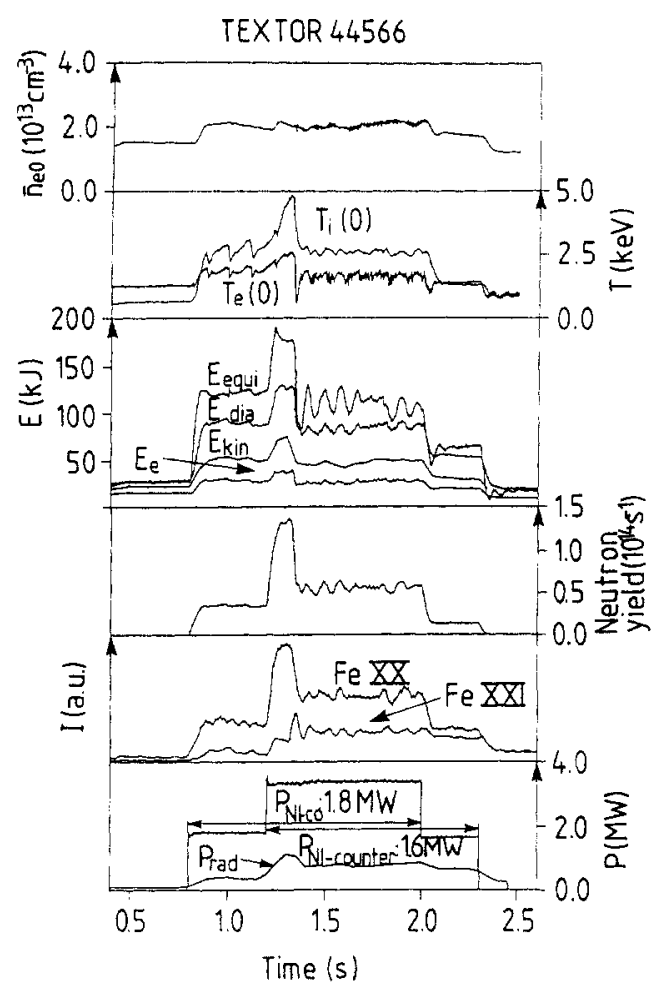

FIG. 22. Plasma parameters as a function of time for a TEXTOR discharge (\#44566) showing a sudden transition from I-mode to L-mode scaling. The same signals as in Fig. 2 are plotted, except for the addition of the neutron source strength.

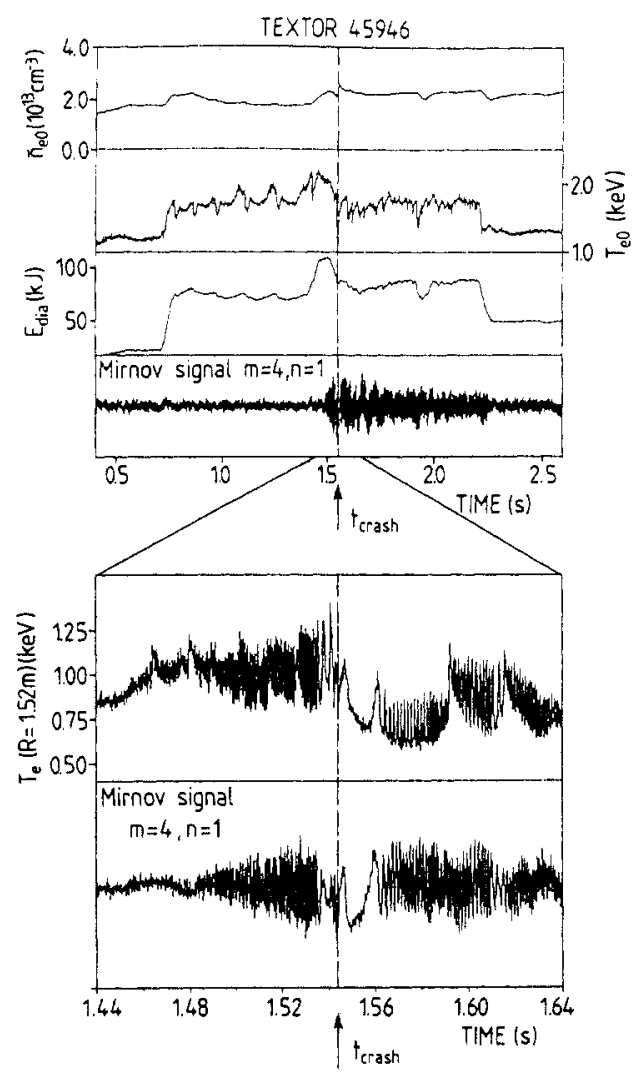

FIG. 23. Illustration of the influence of MHD activity on confinement in an 1-mode discharge (\#45946). Shown are the time evolution of the central line averaged electron density, the central electron temperature (from $E C E$ ), the diamagnetic energy signal and the Mimov signal for the $m=4, n=1$ mode. The lower part gives a more detailed picture of the time evolution around the transition time of the ECE signal at $R=1.52 \mathrm{~m}$ and of the $m=4, n=1$ Mirnov signal.

instabilities can be inferred from the Mirnov signal (e.g. $m=4, n=1$ mode) and the ECE signals. These signals also show a precursor phase just before the temperature crash, and periodic bursts of magnetic oscillations after it, with many $(\mathrm{m}, \mathrm{n})$ components, sometimes exhibiting fishbone-like and sawtooth-like events. These crashes preferentially take place at low currents and densities, indicating the possible role of fast particles in inducing this class of instabilities. Note that the energy already begins to decrease before the temperature crash, at the onset of the MHD activity.

It is interesting to note that the drop of confinement in the case shown in Fig. 22 is accompanied by a sudden collapse of the electron temperature and a minor change in the line averaged density. Figure 24 shows electron temperature profiles for discharge $\# 44566$, for $10 \mathrm{~ms}$ time intervals around the crash time. 


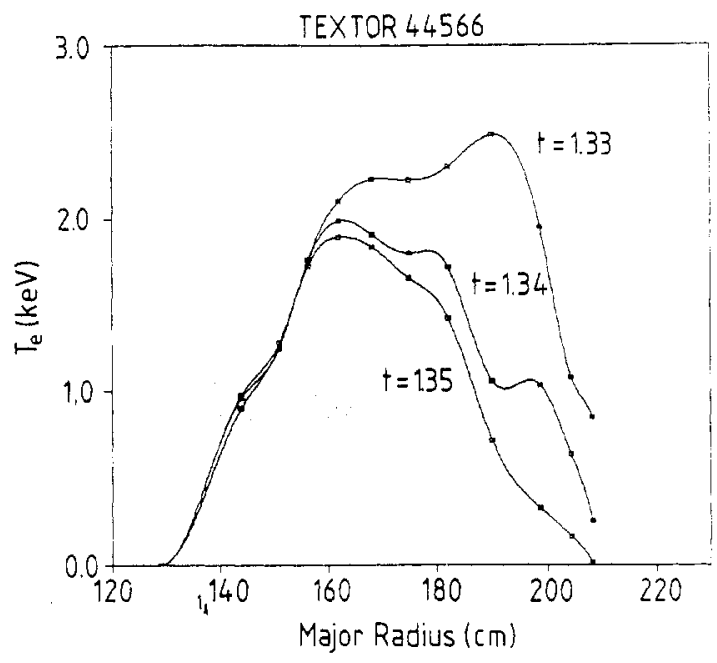

FIG. 24. Illustration of the collapse of the electron temperature profile during the transition from I-mode to L-mode scaling for the discharge in Fig. 22. Shown is a profile before $(t=1.33 \mathrm{~s})$, during $(t=1.34 \mathrm{~s})$ and after $(t=1.35 \mathrm{~s})$ the transition.

TEXTOR 44566

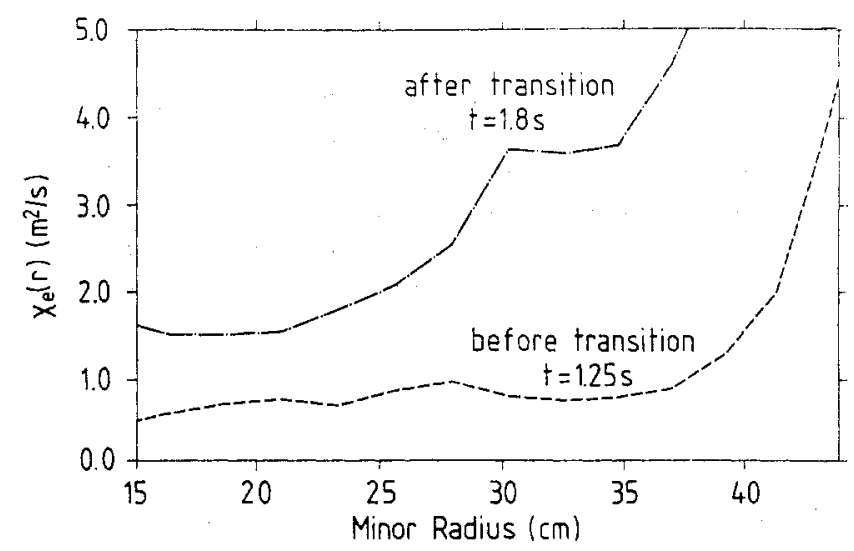

FIG. 25. Results of a transport analysis for the discharge of Fig. 22, showing the increase in the electron thermal diffusivity after the transition from the I-mode to the L-mode.

Upon transition, there is a strong adjustment of the shape of the electron density profile: the mean value of the peaking factor drops and there is strong oscillation of $\gamma_{n}$ around this lower mean value. For the case of Fig. 22, the mean value of $\gamma_{n}$ is reduced from $\sim 3$ before the crash to $\sim 2.2$ after the crash.

Figure 25 shows typical profiles of the electron thermal diffusivity $\chi_{\mathrm{e}}$ during the I-mode scaling phase and the subsequent L-mode scaling phase after a transition.
At all tokamak radii, $\chi_{\mathrm{e}}$ is increased during the transition from I-mode to L-mode scaling. The increase is smallest in the plasma core and becomes more pronounced towards the plasma edge. This result shows that a genuine confinement degradation has taken place, especially in the outer regions of the plasma.

\subsection{Role of recycling}

To illustrate the effect of recycling on confinement, we show in Fig. 26 the confinement time $\tau_{\text {dia }}=E_{\text {dia }} / P_{\text {tot }}$ as a function of $\tau_{p}$, where $\tau_{p}$ is defined as the ratio of the total number of electrons in the discharge to the particle flux on the belt limiter ALT-II. The open symbols represent discharges without MHD activity and suggest a dependence of $\tau_{\mathrm{E}}$ on $\tau_{\mathrm{p}}$, thus indicating the possible role of recycling. However, these results are still of a preliminary nature and should be refined. In order to properly account for plasma dynamics, the analysis should include recycling not only at the limiter but also at other locations. For the data considered here, low recycling conditions are obtained by boronization of the tokamak walls [22].

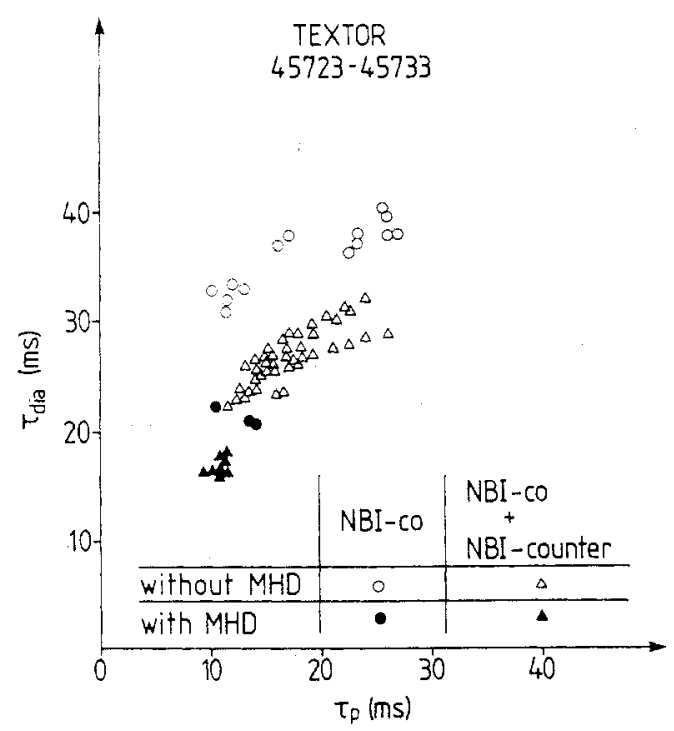

FIG. 26. Relationship between the confinement time derived from the diamagnetic energy, $\tau_{\text {dia }}=E_{\text {dia }} / P_{\text {tot }}$, and the particle confinement time $\tau_{p}$, defined as the ratio of the total number of electrons in the discharge to the particle flux on the belt limiter ALT-II. The open symbols represent discharges in which no MHD activity was observed. The closed symbols correspond to data from post-transition discharges with strong $M H D$ activity. The data are taken from discharges at $I_{p}=285 \mathrm{kA}, B_{t}=2.35 \mathrm{~T}, 1.8<\bar{n}_{e 0}<4.3 \times 10^{13} \mathrm{~cm}^{-3}$, $1.5<P_{N J-c o}<1.9 \mathrm{MW}$ and $2.5<P_{N J-c o}+P_{N / \text {-counster }}<2.8 \mathrm{MW}$. 
The closed symbols in Fig. 26 represent data from post-transition discharges with strong MHD activity. This figure shows also that for a given value of $\tau_{\mathrm{p}}$, the value of $\tau_{\mathrm{E}}$ is much lower when MHD activity is observed.

In Section 4, we have shown that NBI-co + NBIcounter discharges are prone to a decrease of confinement at high density. Recycling is also thought to play a role, since it is observed that less confinement degradation occurs when the high density is reached by wall fuelling rather than by strong gas puffing [23].

\section{CONCLUSIONS}

Improved confinement conditions are observed in the limiter tokamak TEXTOR heated by NBI-co, NBI-co + NBI-counter and NBI-co + ICRH, with the confinement times strongly exceeding those from L-mode scaling and being as favourable as those obtained in ELMy $\mathrm{H}$-mode divertor discharges. The confinement in I-mode discharges improves with $I_{p}$ and scales as 1.68 and $1.81 \times$ ITER L89-P for stationary and transient conditions, respectively. A $\beta_{\mathrm{p}}$ limit is found in TEXTOR which is equal to 1.5 under stationary conditions and to 1.6 for transient phases. This $\beta_{p}$ limit is seen for plasma currents below $300 \mathrm{kA}$ and is reached with a total net heating power of $1.7 \mathrm{MW}$ at $200 \mathrm{kA}$ and $3.5 \mathrm{MW}$ at $300 \mathrm{kA}$. The maximum toroidal beta values reach nearly $1 \%$, i.e. 0.7 times the Troyon limit for TEXTOR (defined as $2.8 \mathrm{I}_{\mathrm{p}} /\left(\mathrm{a} \mathrm{B}_{\mathrm{t}}\right)$ ). There are specific electron density and temperature profiles with a peaked central value and well developed edge pedestals, similar to those observed in $\mathrm{H}$-mode or supershot regimes obtained with NBI-co + NBI-counter heating. To obtain this operational regime, two conditions seem to be necessary: low recycling (in most cases obtained with boronized walls in TEXTOR) and the absence of mode activity. If the latter condition is not met, sudden transitions of the I-mode to lower confinement regimes can occur in discharges heated by NBI-co + NBI-counter and NBI-co + ICRH. These transitions, accompanied and presumably triggered by MHD activity, occur more likely at low $I_{p}$ and $n_{e}$.

\section{ACKNOWLEDGEMENTS}

We would like to express our thanks to Dr. F. Wagner of the Max-Planck-Institut für Plasmaphysik, Garching, for providing electron temperature and density profiles obtained on ASDEX. The continuous support of the team of Dr. M. Korten and the technical staff of LPPERM/KMS and IPP-KFA is gratefully acknowledged. Thanks are also due to Drs R. Goldston and D. McCune of PPPL for providing TRANSP and for their support in using this code system.

\section{REFERENCES}

[1] MESSIAEN, A.M., CONRADS, H., GAIGNEAUX, M., et al., Plasma Phys. Control. Fusion 32 (1990) 889.

[2] CONRADS, H., BERTSCHINGER, G., ESSER, H.G., et al., in Plasma Physics and Controlled Nuclear Fusion Research 1990 (Proc. 13th Int. Conf. Washington, DC, 1990), Vol. 1, IAEA, Vienna (1991) 403.

[3] HAWRYLUK, R.J., in Physics of Plasmas Close to Thermonuclear Conditions (Proc. Course Varenna, 1979), Vol. 1, CEC, Brussels (1980) 19.

[4] ONGENA, J., WEYNANTS, R.R., CONRADS, H., CORNELISSEN, P., KEVER, H., MESSIAEN, A.M., in Controlled Fusion and Plasma Heating (Proc. 17th Eur. Conf. Amsterdam, 1990), Vol. 14B, Part I, European Physical Society (1990) 383.

[5] MESSIAEN, A.M., VAN EESTER, D., KOCH, R., et al., in Fast Wave Current Drive in Reactor Scale Tokamaks (Proc. IAEA Tech. Comm. Mtg Arles, 1991), CEA, Centre d'études de Cadarache, Association Euratom-CEA, Saint Paul-lez-Durance (1991) 325.

[6] YUSHMANOV, P.N., TAKIZUKA, T., RIEDEL, K.S., et al., Nucl. Fusion 30 (1990) 1999.

[7] POST, D.E., BORRASS, K., CALLEN, J.D., et al., in ITER Physics, ITER Documentation Series No. 21, IAEA, Vienna (1991).

[8] CHRISTIANSEN, J.P., CORDEY, J.G., THOMSEN, K., et al., Nucl. Fusion 32 (1992) 291.

[9] LEBEAU, D., KOCH, R., MESSIAEN, A.M., VANDENPLAS, P.E., in Controlled Fusion and Plasma Physics (Proc. 18th Eur. Conf. Berlin, 1991), Vol. 15C, Part III, European Physical Society (1991) 373.

[10] LEBEAU, D., VANDENPLAS, P.E., KOCH, R. MESSIAEN, A.M., Comments Plasma Phys. Control. Fusion 15 (1992) 53

[11] VAN OOST, G., VAN NIEUWENHOVE, R., KOCH, R., et al., Fusion Eng. Des. 12 (1990) 149.

[12] VANDENPLAS, P.E., LEBEAU, D., MESSIAEN, A.M., WEYNANTS, R.R., Comments Plasma Phys. Control. Fusion 15 (1992) 49

[13] GOLDSTON, R.J., BATEMAN, G., BELL, M.G., et al., Bull. Am. Phys. Soc., Ser. II, 35 (1990) 1920.

[14] BURRELL, K.H., in Contributions to the 3rd Workshop on H-mode Physics, JET Joint Undertaking, Abingdon, Oxfordshire (1991) 37.

[15] ASDEX Team, The H-mode of ASDEX, Internal Rep. IPP III/151, Max-Planck-Institut für Plasmaphysik, Garching (1989)

[16] SCHWEER, B., POSPIESZCZYK, A., MANK, G., et al., in Controlled Fusion and Plasma Physics (Proc. 18th Eur. Conf. Berlin, 1991), Vol. 15C, Part IV, European Physical Society (1991) 361; GUNKEL, H., KUSZYNSKI, J.O., POSPIESZCZYK, A., SCHWEER, B., ibid., p. 317. 
[17] STRACHAN, J.D., BITTER, M., RAMSEY, A.T., et al., Phys. Rev. Lett. 58 (1987) 1004.

[18] MEADE, D.M., ARUNASALAM, V., BARNES, C.W., et al., in Plasma Physics and Controlled Nuclear Fusion Research 1990 (Proc. 13th Int. Conf. Washington, DC, 1990), Vol. 1, IAEA, Vienna (1991) 9.

[19] McGUIRE, K.M., ARUNASALAM, V., BELL, M.G., et al., in Plasma Physics and Controlled Nuclear Fusion Research 1986 (Proc. 11th Int. Conf. Kyoto, 1986), Vol. 1, IAEA, Vienna (1987) 421.

[20] McGUiRE, K.M., ARUNASAlaM, V., BARNES, C.W., et al., Plasma Phys. Control. Fusion 30 (1988) 1391.
[21] BELL, M.G., ARUNASALAM, V., BARNES, C.W., et al., in Plasma Physics and Controlled Nuclear Fusion Research 1988 (Proc, 12th Int. Conf. Nice, 1988), Vol. 1, IAEA, Vienna (1989) 27.

[22] WINTER, J., ESSER, H.G., KÖNEN, L., et al., J. Nucl. Mater. 162-164 (1989) 713.

[23] SENGOKU, S., and JFT-2M Team, J. Nucl. Mater. 145-147 (1987) 556.

(Manuscript received 6 August 1992

Final manuscript received 1 December 1992) 